\section{¿QUÉ FORMACIÓN DIDÁCTICA RECIBE EL FUTURO PROFESORADO DE CLARINETE EN EL GRADO SUPERIOR? REFLEXIONES Y PROPUESTA CURRICULAR}

\author{
María del Mar Bernabé Villodre \\ Universidad de Valencia \\ maria.mar.bernabe@uv.es \\ ORCID: http://orcid.org/0000-0001-8983-6602 \\ Miguel Torres Peñarrocha \\ Conservatorio Superior de Música de Murcia \\ migtope@gmail.com \\ ORCID: http://orcid.org/0000-0002-1928-6403
}

Cómo citar este artículo/Citation: Bernabé Villodre, M. M. y Torres Peñarrocha, M. (2017). ¿Qué formación didáctica recibe el futuro profesorado de clarinete en el grado superior? Reflexiones y propuesta curricular. Arbor, 193 (783): a373. doi: http://dx.doi.org/10.3989/arbor.2017.783n1004

Recibido: 21 julio 2014. Aceptado: 13 abril 2016.

RESUMEN: Las sucesivas reformas educativas de las enseñanzas superiores de música han aportado un considerable aumento de la carga lectiva de los futuros profesionales. Sin embargo, esas reformas curriculares no trajeron consigo cambios orientados a la realidad laboral, claramente relacionada con la docencia en diferentes niveles. Este artículo ofrece un análisis comparado de los currículos de las diferentes comunidades autónomas, así como una serie de sugerencias sobre la formación didáctica más conveniente para los titulados en Clarinete, a modo de conclusión.

PALABRAS CLAVE: clarinete; pedagogía del clarinete; didáctica instrumental; formación didáctica; grado superior.

\section{WHAT DIDACTIC TRAINING DO FUTURE TEACHERS OF ADVANCED-LEVEL CLARINET RECEIVE? REFLEXIONS AND CURRICULAR PROPOSAL}

Copyright: @ 2017 CSIC. Este es un artículo de acceso abierto distribuido bajo los términos de la licencia Creative Commons Attribution (CC BY) España 3.0.
ABSTRACT: Successive education reforms of advanced-level music teaching have greatly increased the workload of future professionals. However, these reforms have not brought about curricular changes in the work situation, clearly related to teaching at different levels. This article offers a comparative analysis of the curricula of the different autonomous communities, and concludes with a number of suggestions on how to improve educational training for clarinet graduates.

KEYWORDS: clarinet; clarinet pedagogy; specific didactics; didactic training; advanced-level. 


\section{INTRODUCCIÓN}

La realidad laboral del titulado superior en música le obliga a ejercer como docente, bien en centros de Enseñanza Secundaria Obligatoria (ESO), con más suerte en conservatorios profesionales e incluso superiores, más que como músico profesional. Álvarez González (Las salidas profesionales de un/una violinista) muestra que la salida más clara y realista (quizá sea éste el término que menos quieran oír los recién titulados en música) es la docencia como única vía de inserción laboral posible.

Cuando tiene que ejercer como docente en ESO, el estudiantado que ha cursado sus estudios en los conservatorios superiores de música se encuentra con una situación que se viene arrastrando desde el pasado siglo XX: la equivalencia a licenciatura o grado. En Los conservatorios superiores y la universidad, Pliego de Andrés consideraba ya la necesidad de acercar la organización de los conservatorios al modelo general de las universidades, y no lo consideraba algo realmente complicado (ni económica ni formalmente), debido principalmente a que los estudios musicales formaron parte de la universidad durante seis siglos (Pliego de Andrés, Las enseñanzas superiores de música ante la nueva reforma: análisis y propuestas). Sin embargo, en el año 2012 quedó ratificado que los estudios musicales seguirían siendo equivalentes (recurso número $122 / 2009$, fecha de sentencia 13 de enero de 2012) y, debido a esto, las personas que cuentan con grados en primaria (mención música) o bien con grados en musicología u otras especialidades instrumentales cursadas en algunas universidades privadas que ofertan algunas especialidades instrumentales y no instrumentales como grados universitarios, están los primeros en las listas de acceso a esta formación de máster de profesorado (puesto que se exige ser licenciado o graduado). De manera que el alumnado con su título superior de música (equivalente a licenciatura o grado) se ve en inferioridad de condiciones, también cuando quiere acceder a estudios de doctorado (másteres de investigación). Pero todo esto supone una polémica que no nos ocupa, aunque debe mencionarse para situar la problemática trabajada en este artículo.

Lo significativo de todo lo comentado anteriormente es el hecho de que la formación didáctica del alumnado de especialidades instrumentales queda reducida a la recibida en el máster de profesorado (antiguo certificado de aptitud pedagógica, CAP), formación que no responde a las características y necesidades de los centros de enseñanza musicales, así como a las distintas especificidades de cada especialidad instrumental. Entonces ¿dónde se forman pedagógicamente para atender a sus futuros estudiantes de instrumento?; ¿ ¿el currículo de su respectiva especialidad les prepara para actuar como docentes instrumentales? Estas preguntas eran de fácil solución hasta que la última reforma educativa eliminó la presencia de la especialidad de pedagogía del instrumento, de modo que ahora se ha reducido a la "buena voluntad" del alumnado el elegir asignaturas de la especialidad de pedagogía del lenguaje y la educación musical, y a la formación e interés del profesorado del conservatorio superior, que preparará a su alumnado en esta dirección como otra posibilidad laboral más.

La tradición didáctica de los currículos de las especialidades instrumentales no ha sido tal, puesto que no se contaba con asignaturas en esta dirección formativa. Esto suponía y (tristemente) sigue suponiendo que los titulados en especialidades instrumentales no cuentan con los recursos necesarios para hacer frente a la labor docente. Jorquera (2002) considera que los métodos para instrumentos que se publicaron en el siglo XIX tuvieron la intencionalidad de enfocar la labor docente de una forma más rigurosa y orientada a la solución de determinados problemas técnicos, aunque después terminase por producirse una separación entre el estudio de la técnica y otros ejercicios de esos métodos y las obras musicales. Aunque se vuelve siempre al mismo punto de partida: el alumnado termina por imitar, por repetir intuitivamente los principios que recibió de sus maestros (Palacios, 1998) porque no se le ha hecho reflexionar sobre otras posibilidades metodológicas.

Este artículo se ocupa precisamente de analizar las carencias en torno a la formación didáctica de los futuros docentes, para demostrar lo necesario de la misma; ya que un elevadísimo número de alumnado terminará por decantarse por esta opción laboral, debido a que no existen suficientes puestos para la interpretación profesional (bandas municipales, orquestas municipales...). De manera que necesita contar con conocimientos de tipo general (sociología, psicología, antropología) (Jorquera, 2002).

A todo esto viene a sumarse el hecho de que el alumnado de la sociedad actual demanda una atención más especializada, más personalizada, acorde con los importantes avances técnicos que se han conseguido en otros ámbitos educativos. Desde nuestra experiencia docente con alumnado de enseñanzas elementales y profesionales, hemos podido comprobar que el alumnado exige explicaciones muy razonadas sobre todo 
el proceso que da lugar a la obra musical, sobre los motivos que llevan a una u otra interpretación... Esto es importante porque permite comprender la música como un producto no sólo artístico, de la "inspiración" del ser humano, como una actividad recreativa (Pliego de Andrés, De músicas, normas y conservatorios), sino también como un fruto de su razonamiento científico.

Se trata de favorecer el paso de una clase donde el alumnado termina imitando la interpretación realizada por el docente, forma tradicional de enseñar que comprendía estrategias repetitivas e imitativas (Pozo, Bautista y Torrado, 2008), y pasar a razonar y comprender lo que le lleva a interpretar de una u otra forma porque el docente parte de los recursos didácticos necesarios para ello, orientados a cada perfil de alumnado: como señala Palacios (1998), la enseñanza de la música instrumental debe establecerse de forma diferenciada en enseñanza instrumental de iniciación y enseñanza instrumental de perfeccionamiento, atendiendo al público al que va dirigida para responder mejor a sus necesidades.

Si se realiza una búsqueda bibliográfica sobre la didáctica instrumental en los conservatorios de música, veremos cómo se obtienen muy escasos resultados, por ejemplo: Bernabé (2013), Muñoz Muñoz (2009), Cabrera (2009). Sin embargo, la necesidad de formar a los instrumentistas también como docentes hace imprescindibles artículos como el que aquí se presenta, puesto que permiten asentar las bases de una importante reflexión previa al desarrollo de investigaciones orientadas a dar con los caminos más adecuados para mejorar la interpretación del estudiante a partir de unas prácticas pedagógicas reflexivas y razonadas, y no meramente imitativas o intuitivas. En este sentido, Pozo, Bautista y Torrado (2008) vienen reclamando un cambio en las concepciones implícitas sobre el proceso de enseñanza/aprendizaje de la interpretación musical en los conservatorios, que tiene mucho que ver con la evolución de la sociedad que ya fue comentada en párrafos anteriores.

Se pretende que este artículo contribuya a reforzar la presencia y el aumento de un mayor número de investigaciones relacionadas con la didáctica instrumental en los conservatorios de música, en la línea de trabajos de análisis de materiales (de piano) como el ya realizado por Roldán Alcázar (2010) o el interesante trabajo de Bautista y Pérez-Echeverría (2008) sobre las percepciones de enseñanza del profesorado de instrumento, más que en la línea de la psicología de la música (por ejemplo, Holgado, Navas y Marco, 2013) porque no pertenecemos a la rama de la psicología para poder investigar con propiedad suficiente en esta dirección. Las experiencias de investigación-acción que puedan estar desarrollándose en las aulas de los conservatorios, deben evitar convertirse en modelos operativos del cambio sin bases metodológicas sólidas (Nuño Guerrero, 2010). Se trata de investigar desde nuestro campo, para nuestro campo y con nuestras herramientas y capacidades características como especialistas en música, al mismo tiempo que se intenta evitar que los conservatorios "conserven" (tal era su función) "tradiciones docentes" que no se adecúan a los tiempos actuales (Pozo, Bautista y Torrado, 2008).

\section{LOS CURRÍCULOS DE LAS ENSEÑANZAS MUSICALES}

De acuerdo con el Real Decreto 1542/1994, de 8 de julio, por el que se establece las equivalencias entre los títulos de música anteriores a la Ley Orgánica $1 / 1990$, de 3 de octubre, de Ordenación General del Sistema Educativo (LOGSE), y los establecidos en dicha ley, los estudios superiores musicales desarrollados en los distintos conservatorios superiores de música debían seguir sus dictados. Sin embargo, el grado de competencia autonómica supuso reformas curriculares muy diferenciadas, que serán comentadas en epígrafes posteriores, que permitieron dotar de mayor o menor importancia a determinadas materias.

Aunque las actuaciones reformadoras iniciadas por la Ley Orgánica 1/1990, de 3 de octubre, de Ordenación General del Sistema Educativo supusieron un enfoque totalmente diferente para el estudiantado de los conservatorios superiores de música, la Ley Orgánica 2/2006, de 3 de mayo, de Educación (LOE) continuó esa línea iniciada de aumento de carga lectiva para el instrumentista. Esto tuvo mucho que ver con la Declaración de Bolonia, que llevó a las enseñanzas de régimen especial a tratar de igualar sus currículos, estructuración, etc. con el ámbito universitario (aunque después se les prohibiese considerarse estudios de grado (Recurso número 122/2009, fecha de sentencia: 13 de enero de 2012).

Debe señalarse que la reforma del año 2002, la Ley Orgánica 10/2002, de 23 de diciembre, de Calidad de la Educación (LOCE), no trajo consigo un cambio en la normativa de los conservatorios superiores de música, puesto que la primera promoción LOGSE que iniciaba sus estudios en el curso 2001-2002 y las posteriores cursó estudios en dicho plan hasta la introducción de los cambios de la LOE, en el año 2006 (la primera promoción LOGSE finalizó estudios en el curso académico 2004-2005). Zaldívar (2005) señalaba que las modificaciones de los planes de estudios de acuerdo con 
la LOCE estaban en preparación en el año 2005; sin embargo, estos no llegarían a aparecer al derogarse la LOCE por la promulgación de la LOE en el año 2006. La Ley Orgánica 8/2013, de 9 de diciembre, para la mejora de la calidad educativa (LOMCE) también está afectando a los conservatorios superiores de música de distinta forma atendiendo a la competencia autonómica; pero, igual que en los centros de educación obligatoria, la polémica parece estar servida.

\subsection{Reforma LOGSE}

El Real Decreto 617/1995, de 21 de abril, por el que se establecen los aspectos básicos del currículo del grado superior de las enseñanzas de música y se regula la prueba de acceso a estos estudios y la Orden de 25 de junio de 1999, por la que se establece el currículo del grado superior de las enseñanzas de música aparentemente supuso un cambio radical, que intentaba mejorar las capacidades interpretativas del músico a través del estudio obligatorio de determinadas materias, y también trataba de favorecer un aprendizaje constructivista que nunca se había dado en los conservatorios superiores de música (Pozo, Bautista y Torrado, 2008). Sin embargo, este considerable aumento de materias y su distribución en optativas y de libre elección no agradó a todo el mundo: los datos recogidos por Álvarez González muestran que el alumnado consideraba que había demasiadas asignaturas que restaban tiempo de estudio interpretativo; a esta opinión negativa sobre el currículum también se suma el profesorado (Cid, 2012).

Precisamente esa aumentada carga teórico-práctica iba destinada a evitar posibles carencias interpretativas y también didácticas: en este sentido, la investigación de Cid (2012) muestra que el alumnado es consciente de sus carencias/lagunas en el ámbito pedagógico, que podrían evitarse al seleccionar asignaturas relacionadas con la didáctica. Parece ser que en ningún momento ese aumento de asignaturas teórico-prácticas fue visto como positivo para la mejora de la interpretación, objetivo por el que fueron incorporadas a los currículos de cada especialidad instrumental. Orlandini (2012) considera que la interpretación de una frase musical precisa que el estudiante tenga conocimientos precisos de entorno histórico, estilo de la época y del país... Y, así, el currículo se amplió con las distintas reformas para dar mayor sentido y coherencia a las interpretaciones musicales; además de que dicha ampliación, permitió al alumnado confeccionar su formación o perfil profesional exclusivo (Veintimilla, 2010), aspecto importante porque posibilitaba su formación didáctica al seleccionar asigna- turas de titulaciones como pedagogía del lenguaje y la educación musical.

De acuerdo con el Real Decreto 617/1995 y con la Orden de 25 de junio de 1999, las asignaturas de clarinete eran: clarinete, análisis, educación auditiva, historia de la música, organología, práctica armónicacontrapuntística, música de cámara, orquesta/banda, quinteto de viento, fundamentos de mecánica y mantenimiento, interpretación histórica de la música antigua, lectura e interpretación de la música contemporánea, repertorio orquestal, piano, repertorio con pianista acompañante, y técnica de respiración y control muscular. Y a partir de esto cada centro contaba con cierta libertad en la reestructuración curricular, atendiendo al grado de competencia autonómica. Así, cada uno de los tres conservatorios superiores de la Comunidad Valenciana (regulados por el Decreto 132/2001, de 26 de julio de 2001, del Gobierno Valenciano, por el que se establece el currículo del grado superior de música en la Comunidad Valenciana y el acceso a dichas enseñanzas), introdujo algunas (mínimas) variaciones en las denominaciones originales de las materias troncales y obligatorias (estética / estética de la música y orquesta / orquesta-conjunto), dentro del grado de libertad otorgado a cada centro para la elaboración de su currículum (repertorio del clarinete se oferta en Castellón, pero no en Alicante ni en Valencia), más visible en las asignaturas optativas y de libre elección. En Galicia, a partir del Decreto $183 / 2001$, de 19 de julio, por el que se establece el currículo del grado superior de las enseñanzas de música y el acceso a dicho grado, la única diferencia entre los conservatorios superiores de La Coruña y de Vigo, es que este último incluyó la asignatura segundo instrumento y repentización.

En Cataluña, esta reforma LOGSE no trajo diferencias ni en la denominación ni en el planteamiento de las asignaturas (troncales-obligatorias) entre sus dos centros (Conservatorio Superior de Música del Liceo y Escuela Superior de Música de Cataluña). Mientras que, en la Comunidad Autónoma de Andalucía, la Orden de 16 de julio de 2002, por la que se aprueba el plan de estudios de las enseñanzas del grado superior de música del Conservatorio Superior de Música Manuel Castillo, de Sevilla, la Orden de 16 de julio de 2002, por la que se aprueba el plan de estudios de las enseñanzas del grado superior de música del Conservatorio Superior de Música de Málaga, Orden de 16 de julio de 2002, por la que se aprueba el plan de estudios de las enseñanzas del grado superior de música del Conservatorio Superior de Música Rafael Orozco, 
de Córdoba, Orden de 16 de julio de 2002, por la que se aprueba el plan de estudios de las enseñanzas del grado superior de música del Conservatorio Superior de Música Victoria Eugenia, de Granada, y su Decreto $56 / 2002$, de 19 de febrero, por el que se establece el currículo del grado superior en las enseñanzas de mú- sica en los conservatorios de Andalucía, propiciaron que cada conservatorio (a excepción de Jaén, que se funda con la LOE) propusiese algunos pequeños cambios en las nomenclaturas de las troncales y obligatorias, así como en la oferta de las optativas y de libre elección (tabla 1).

Tabla 1. Denominaciones de las asignaturas troncales y obligatorias del título superior de clarinete en los conservatorios superiores de música de Andalucía.

\begin{tabular}{|c|c|c|c|}
\hline Córdoba & Granada & Málaga & Sevilla \\
\hline Análisis musical & Análisis musical & Análisis musical & Análisis musical \\
\hline $\begin{array}{c}\text { Sociología y estética de la } \\
\text { música }\end{array}$ & $\begin{array}{c}\text { Sociología y estética de la } \\
\text { música }\end{array}$ & $\begin{array}{c}\text { Sociología y estética de la } \\
\text { música }\end{array}$ & $\begin{array}{c}\text { Sociología y estética de la } \\
\text { música }\end{array}$ \\
\hline Teoría de las formas & Teoría de las formas & Teoría de las formas & Teoría de las formas \\
\hline--- & $\begin{array}{l}\text { Lenguajes de la música } \\
\text { contemporánea }\end{array}$ & $\begin{array}{l}\text { Taller de música } \\
\text { contemporánea }\end{array}$ & --- \\
\hline Educación auditiva & Educación auditiva & Educación auditiva & Educación auditiva \\
\hline Historia de la música & Historia de la música & Historia de la música & Historia de la música \\
\hline--- & $\begin{array}{c}\text { Historia de la música } \\
\text { española }\end{array}$ & $\begin{array}{c}\text { Historia del pensamiento } \\
\text { musical }\end{array}$ & --- \\
\hline Clarinete & Clarinete & Clarinete & Clarinete \\
\hline Música de cámara & Música de cámara & Música de cámara & Música de cámara \\
\hline Quinteto de viento & Quinteto de viento & Quinteto de viento & Quinteto de viento \\
\hline Banda & Banda & Banda & Banda \\
\hline Orquesta sinfónica & Orquesta sinfónica & Orquesta sinfónica & Orquesta sinfónica \\
\hline Piano complementario & Piano complementario & Piano complementario & Piano complementario \\
\hline $\begin{array}{l}\text { Repertorio con pianista } \\
\text { acompañante }\end{array}$ & $\begin{array}{l}\text { Repertorio con pianista } \\
\text { acompañante }\end{array}$ & $\begin{array}{l}\text { Repertorio con pianista } \\
\text { acompañante }\end{array}$ & $\begin{array}{l}\text { Repertorio con pianista } \\
\text { acompañante }\end{array}$ \\
\hline $\begin{array}{c}\text { Comentario de audición } \\
\text { musical }\end{array}$ & --- & --- & --- \\
\hline Armonía & Armonía & Armonía & Armonía \\
\hline--- & --- & Contrapunto & --- \\
\hline Historia de la orquesta & -- & --- & --- \\
\hline $\begin{array}{l}\text { Historia de los instrumentos } \\
\text { de viento madera }\end{array}$ & --- & --- & --- \\
\hline Repertorio orquestal & $\begin{array}{l}\text { Estudio teórico del } \\
\text { repertorio de viento }\end{array}$ & --- & --- \\
\hline--- & Lectura a vista y transporte & --- & --- \\
\hline $\begin{array}{l}\text { Ergonomía técnica postural } \\
\text { del músico }\end{array}$ & $\begin{array}{l}\text { Formación corporal, } \\
\text { comunicación y escena }\end{array}$ & --- & --- \\
\hline--- & --- & Didáctica de la música & --- \\
\hline
\end{tabular}

Fuente: elaboración propia a partir de los datos extraídos del Decreto 56/2002 y de las Órdenes de 16 de julio de 2002 
La transformación más importante de la LOGSE fue la aparición de la especialidad de pedagogía del clarinete, que garantizaba una formación didáctica adecuada a la realidad laboral (docencia) de estos futuros titulados superiores (Álvarez González); aunque, no todos los centros la ofertaban, como puede verse en la Tabla 2, que presenta una comparativa de acuerdo con una clasificación en áreas de conocimiento (tres categorías: interpretación, formación general y formación didáctica) y un desglose en asignaturas (troncales y obligatorias) que permite distinguir qué Comunidades Autónomas insistían más en la formación didáctica del instrumentista y cuáles sumaban la formación didáctica a la misma especialidad de interpretación del clarinete (véase tabla 1. Por ejemplo, en Málaga se ofertaba didáctica de la música).

\subsection{Reforma LOE}

El Espacio Europeo de Educación Superior (EEES) supuso una positiva readaptación de los currículos de la LOGSE. Principalmente, se trataba de cambiar esa visión de que para el músico lo más importante es hacer música (Veintimilla, 2010) y, por tanto, lo teórico-práctico no tenía lugar en su currículo formativo, por una visión en la que la ampliación de materias y años de estudios supusiese una mejora de la calidad interpretativa, al contar con suficientes conocimientos para comprender la música. Aunque todos estos cambios que en las enseñanzas obligatorias llegaban con gran rapidez en los conservatorios de música y el resto de centros artísticos tuvieron que esperar leyes y legislaturas posteriores (Pliego de Andrés, Los conservatorios de música en el proyecto de Ley Orgánica de Educación), en la misma línea de retraso y subestimación que son habituales para las denominadas (tras la LOGSE) como enseñanzas de régimen especial.

El Real Decreto 1614/2009, de 26 de octubre, por el que se establece la ordenación de las enseñanzas artísticas superiores reguladas por la Ley Orgánica 2/2006, de 3 de mayo, de Educación, consideraba las enseñanzas artísticas superiores con la estructura de créditos universitarios, de acuerdo con la normativa del EEES. El Real Decreto 631/2010, de 14 de mayo, por el que se regula el contenido básico de las enseñanzas artísticas superiores de grado en música establecidas en la Ley Orgánica 2/2006, de 3 de mayo, de Educación, ampliaba el grado de competencias del instrumentista, aunque (nuevamente) sin referencias a su formación didáctica. Para comprobar estos cambios LOGSE-LOE se presentan las Tablas 3 y 4 que pueden compararse con los datos aportados en epígrafes anteriores. En ellas puede comprobarse que cada Co- munidad Autónoma introdujo las modificaciones que consideró pertinentes en la especialidad de clarinete respecto a la normativa citada; no obstante, resulta curioso que los análisis realizados hasta el momento muestran que muy pocos vieron necesario ampliar (o incluir) la formación didáctica en sus titulados.

En este sentido de modificaciones del documento ministerial, en el caso de las Comunidades Autónomas de Andalucía, Comunidad Valenciana, Galicia y Cataluña, se ha partido de las provincias de La Coruña, Granada, Valencia y Barcelona (Liceo) por los siguientes motivos: en el caso de Barcelona, porque la Escuela Superior de Música de Cataluña es privada; en el caso de La Coruña, porque era más completo que el de Vigo; igual que sucedía en los de Granada y Valencia que, si bien compartían asignaturas con el resto de provincias de su respectiva comunidad, habían incluido unas cuantas más relevantes para la formación del instrumentista.

Y, en cuanto a los cambios más significativos LOGSELOE en la especialidad de pedagogía del clarinete, la Tabla 5 permite comprobar cómo muchas Comunidades Autónomas otorgaron peso a la formación didáctica específica y eliminaron elementos interpretativos, pero otras añadieron formación didáctica a la formación instrumental. Tanto en unos casos como en otros lo importante es constatar que se estaba dando especial importancia a la formación profesional docente del clarinetista. Debe señalarse que algunas Comunidades Autónomas, como Madrid (Decreto 36/2010) o Navarra (Orden Foral 110/2010), dejaron de ofertar la pedagogía del clarinete y ofertaron únicamente la especialidad de pedagogía del lenguaje y la educación musical; mientras que Asturias comienza a ofertarla (Resolución de 9 de julio de 2010) cuando no la ofertaba durante la LOGSE (estas no han sido incluidas al no poder realizarse una comparación entre planes de estudios, como en el resto de casos incluidos en la citada Tabla 4).

\section{FUNDAMENTACIÓN PANORÁMICA: REALIDAD DIDÁCTICA DE LOS CENTROS DE EDUCACIÓN SUPERIOR MUSICAL}

Los cambios curriculares han sido muy significativos desde la aparición de la LOGSE hasta las reformas de la LOE, y también lo están siendo con la LOMCE aprobada en 2013. En los siguientes epígrafes se mostrará un análisis detallado de estos cambios que se iniciaron con la LOGSE, que trató de hacer comprender al estudiante que la titulación exigía una dedicación exclusiva como el resto de licenciaturas universitarias (Veintimilla, 2010), aunque luego se produjese esa ratificación negativa sobre las titulaciones de música como titulaciones de grado. 


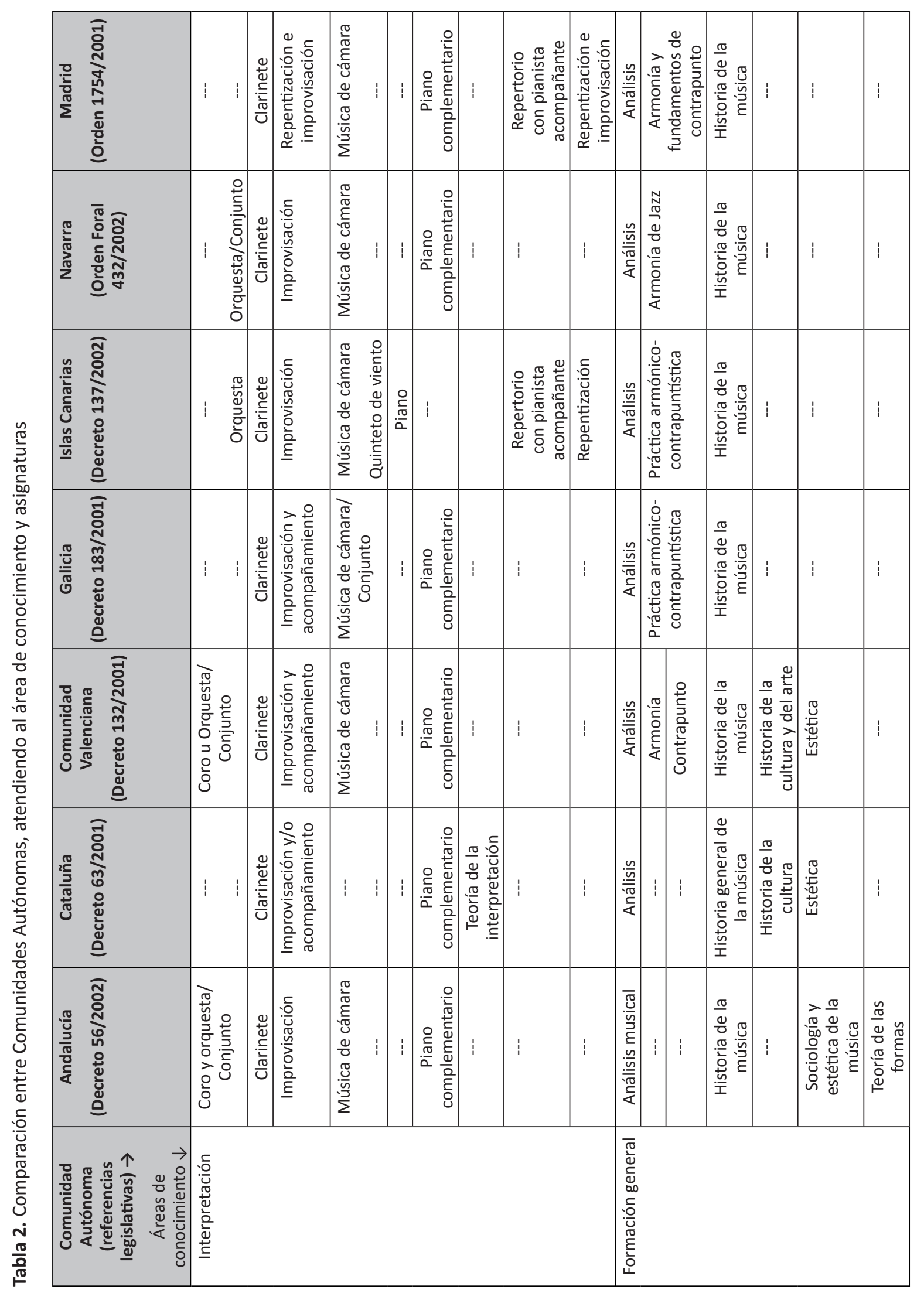




\begin{tabular}{|c|c|c|c|c|c|c|c|c|c|c|c|c|}
\hline $\mid$ & 1 & 1 & 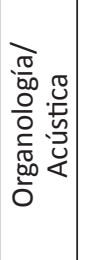 & 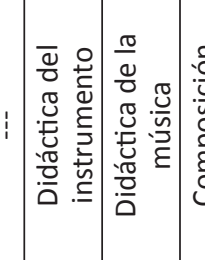 & & 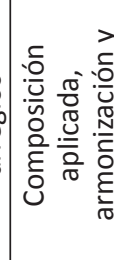 & 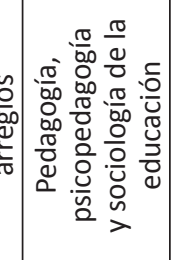 & 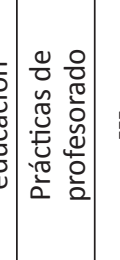 & & 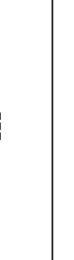 & ! & 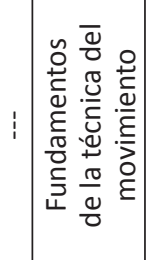 \\
\hline $1: 1$ & 1 & 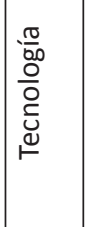 & 1 & 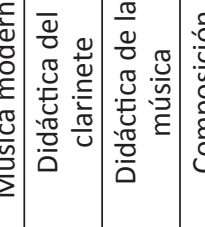 & & 1 & 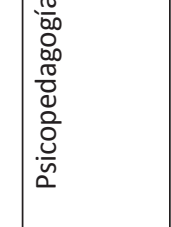 & 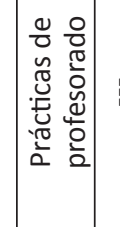 & & 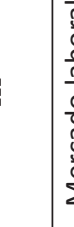 & 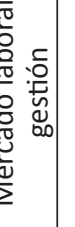 & \\
\hline 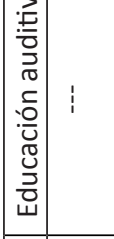 & 1 & 1 & 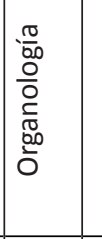 & 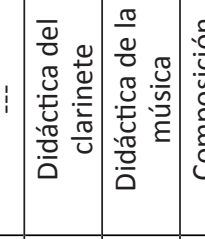 & & 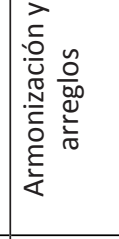 & 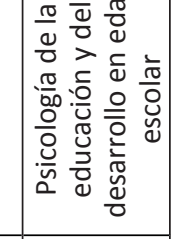 & $\mid$ & & 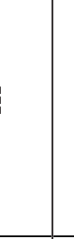 & : & 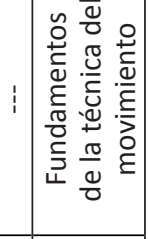 \\
\hline 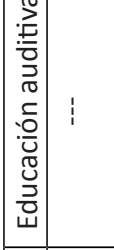 & 1 & : & 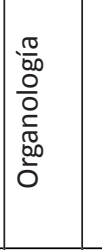 & 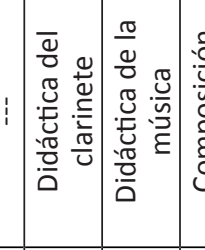 & & 1 & 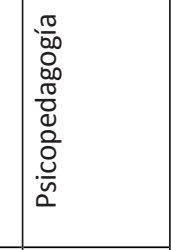 & 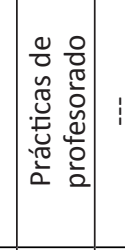 & & 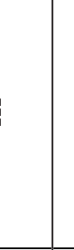 & : & \\
\hline 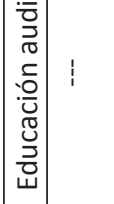 & 1 & 1 & 1 & 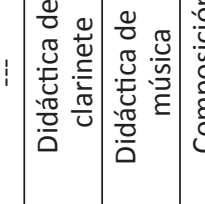 & & : & 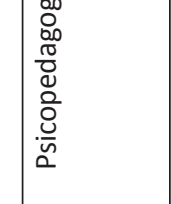 & $\mid$ & & 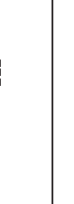 & 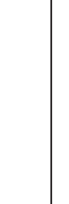 & 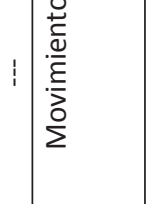 \\
\hline 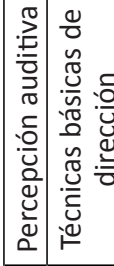 & 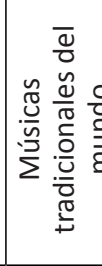 & 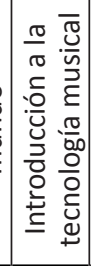 & 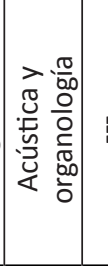 & 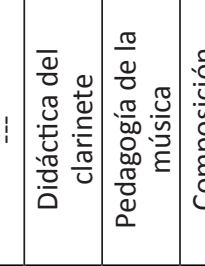 & & 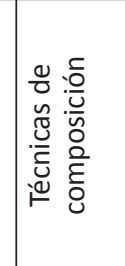 & 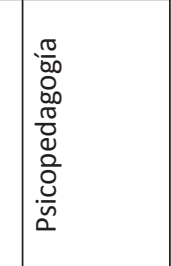 & 1 & 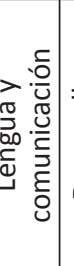 & & & 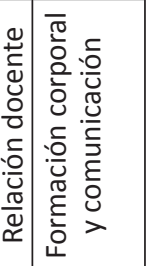 \\
\hline 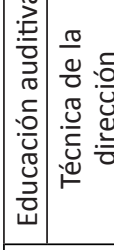 & & & : & 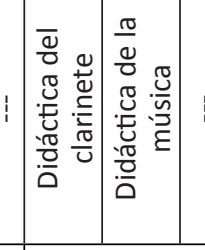 & & 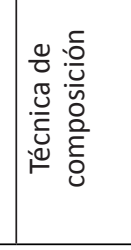 & 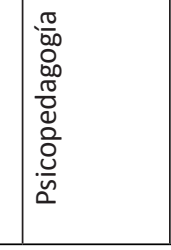 & 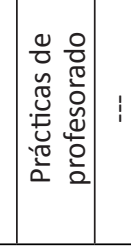 & & & : & 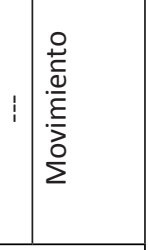 \\
\hline & & & & 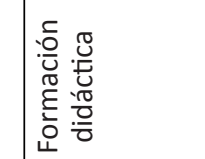 & & & & & & & & \\
\hline
\end{tabular}




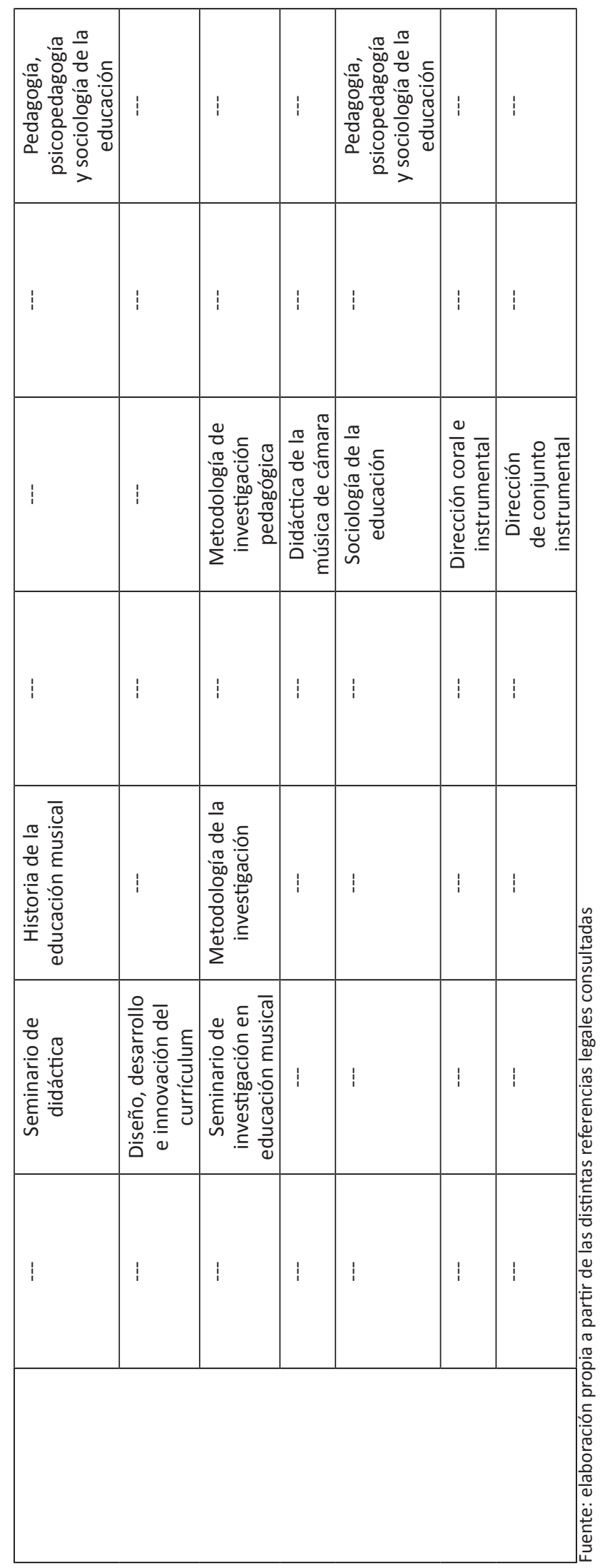

ARBOR Vol. 193-783, enero-marzo 2017, a373. ISSN-L: 0210-1963

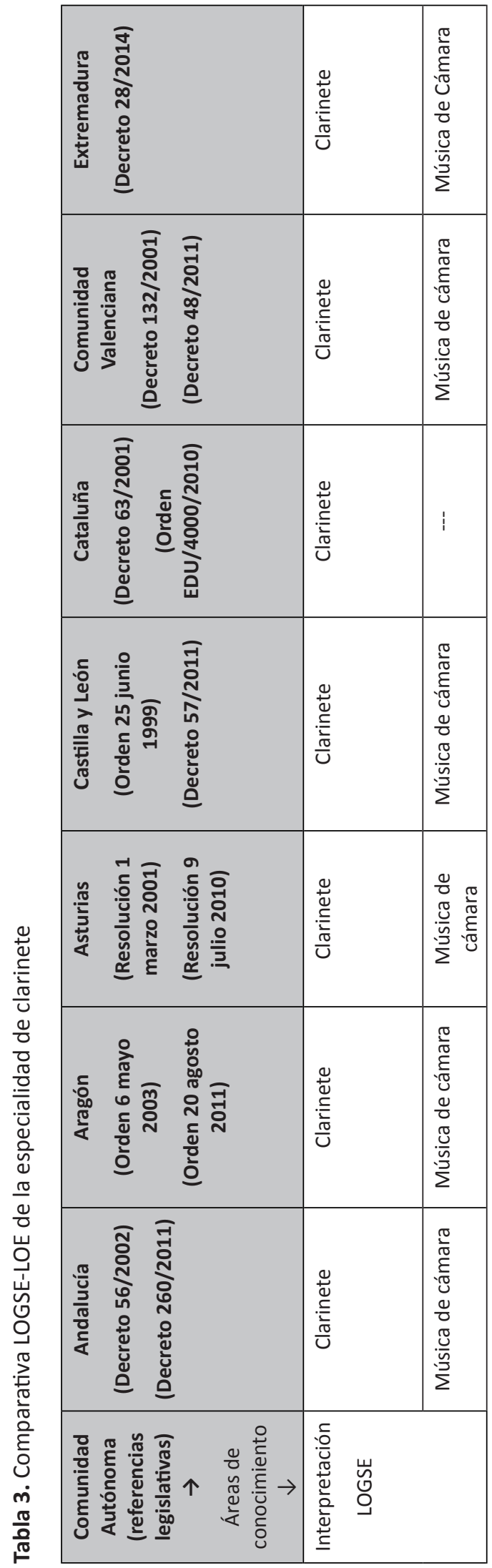

doi: http://dx.doi.org/10.3989/arbor.2017.783n1004 


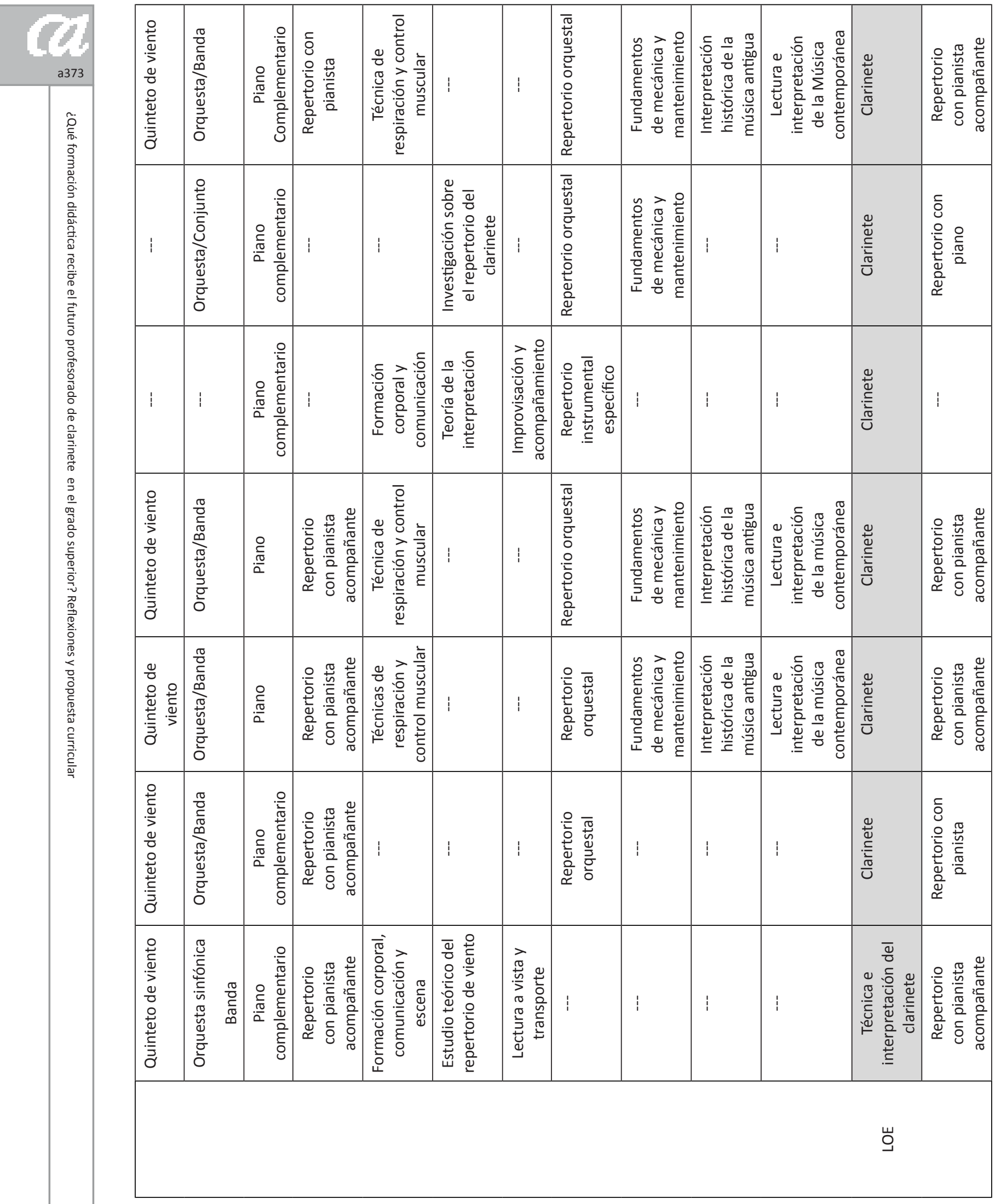




\begin{tabular}{|c|c|c|c|c|c|c|c|c|c|c|c|c|c|c|}
\hline 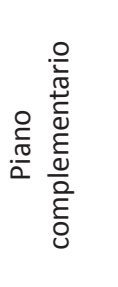 & 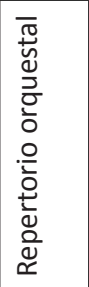 & 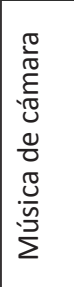 & & & 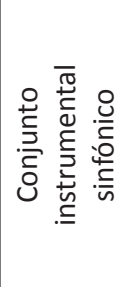 & 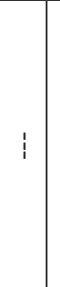 & 1 & 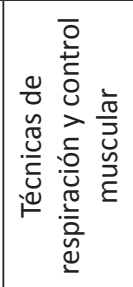 & & : & & & 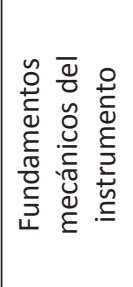 & 1 \\
\hline 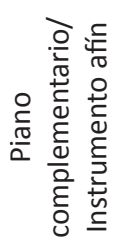 & : & 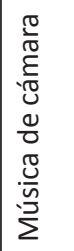 & & & 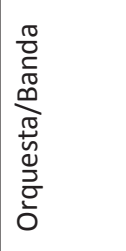 & 1 & i & 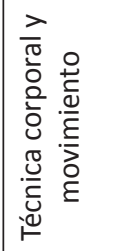 & & i & & & 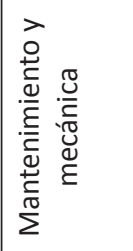 & 1 \\
\hline 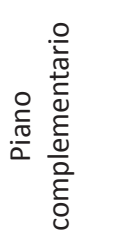 & 1 & 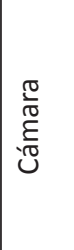 & & & 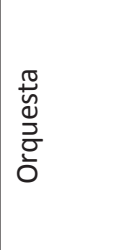 & 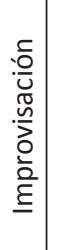 & 1 & 1 & & i & & & 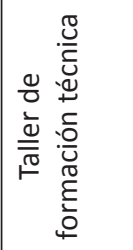 & ல \\
\hline 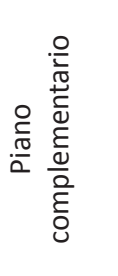 & ! & ! & & & 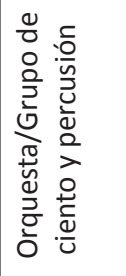 & 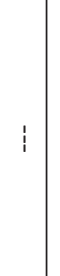 & : & 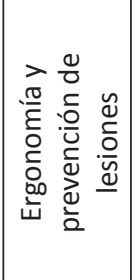 & 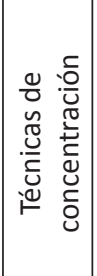 & : & & & 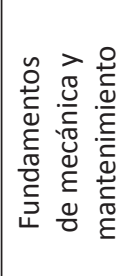 & ○े \\
\hline 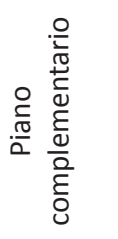 & 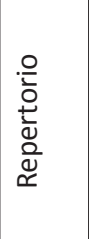 & 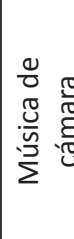 & & & 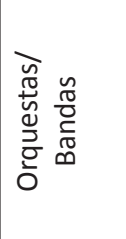 & 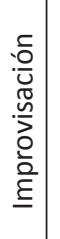 & 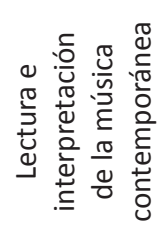 & 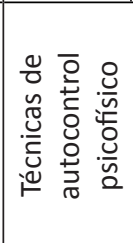 & & : & & & 1 & 1 \\
\hline 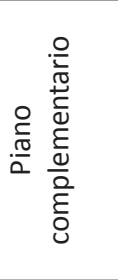 & 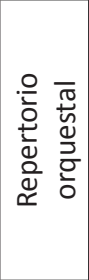 & 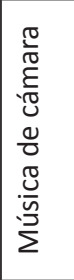 & 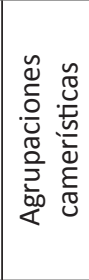 & 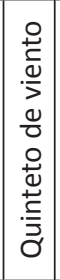 & 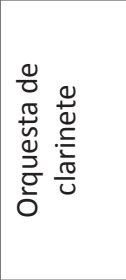 & 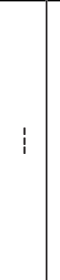 & : & 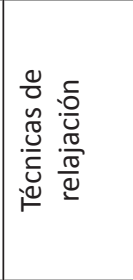 & & 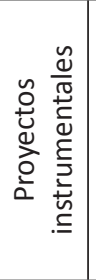 & 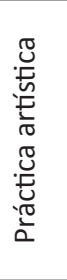 & 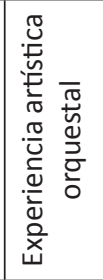 & i & 1 \\
\hline 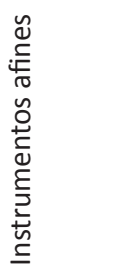 & 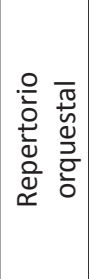 & 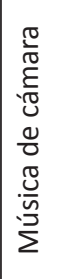 & 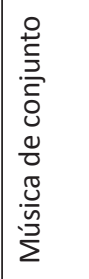 & & 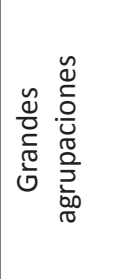 & 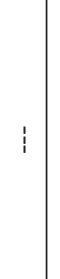 & 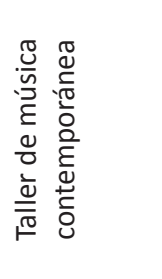 & 1 & & 1 & & & 1 & 1 \\
\hline
\end{tabular}




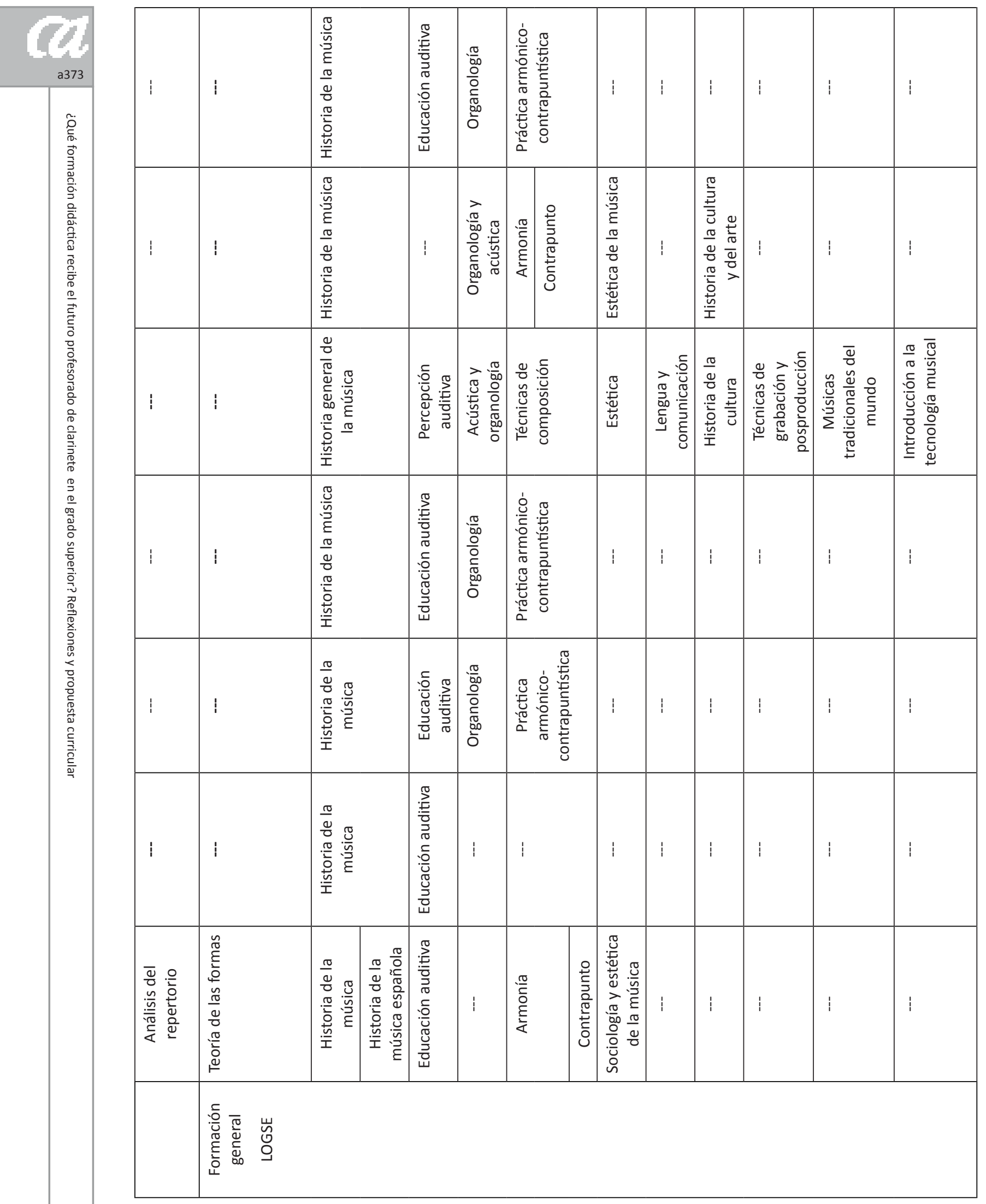




\begin{tabular}{|c|c|c|c|c|c|c|c|c|c|c|c|c|c|}
\hline 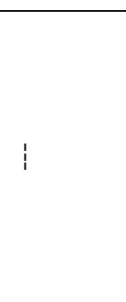 & 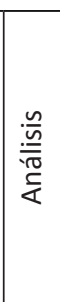 & 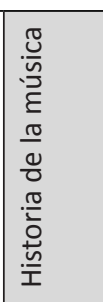 & 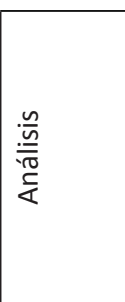 & 1 & 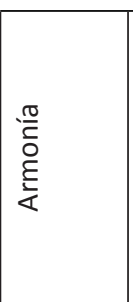 & : & 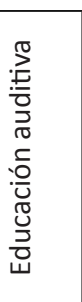 & 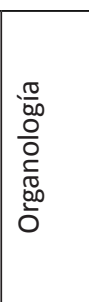 & 1 & : & i & : & 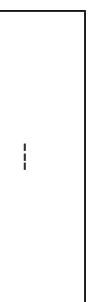 \\
\hline i & 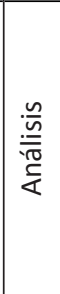 & 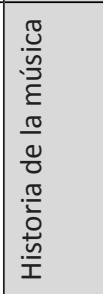 & 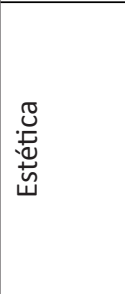 & 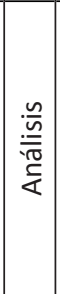 & 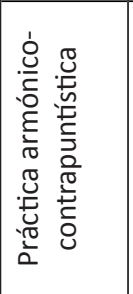 & 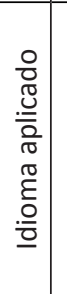 & 1 & 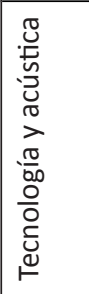 & 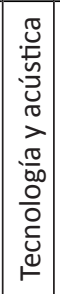 & i & i & i & i \\
\hline : & 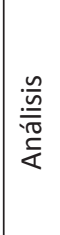 & 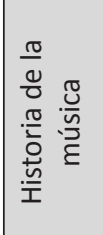 & 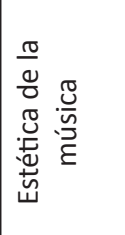 & 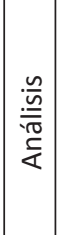 & 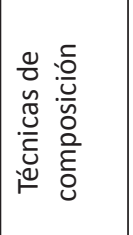 & 1 & 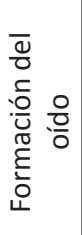 & 1 & $:$ & 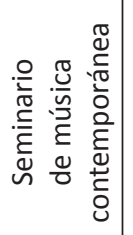 & I & 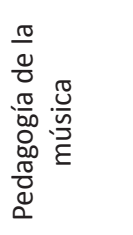 & 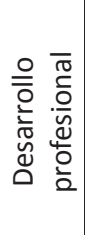 \\
\hline : & 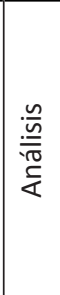 & 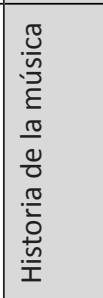 & i & $!$ & 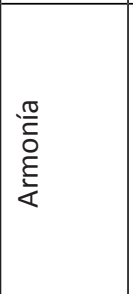 & 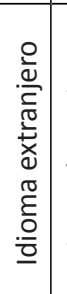 & 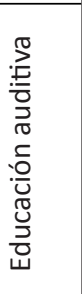 & 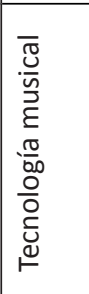 & 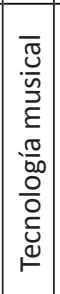 & ! & i & : & 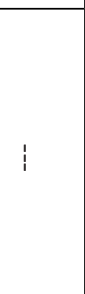 \\
\hline 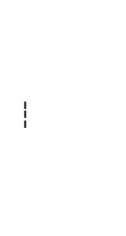 & 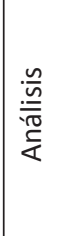 & 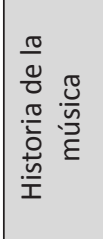 & 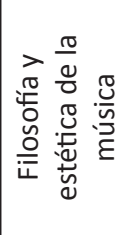 & 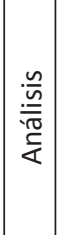 & 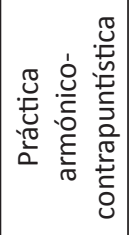 & 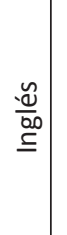 & $:$ & 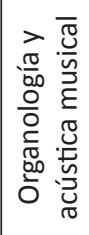 & $:$ & $:$ & 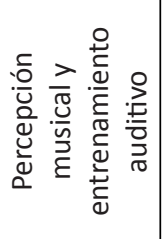 & : & 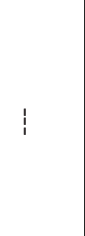 \\
\hline 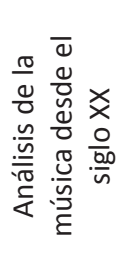 & 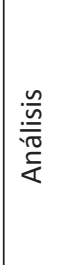 & 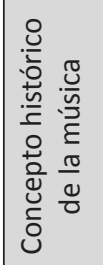 & $i$ & 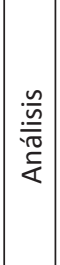 & $i$ & 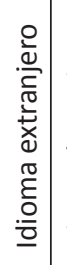 & 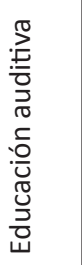 & 1 & 1 & 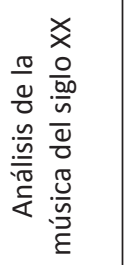 & i & 1 & 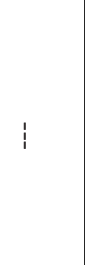 \\
\hline 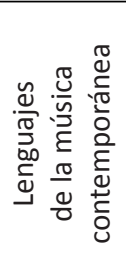 & 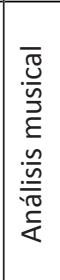 & 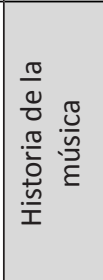 & 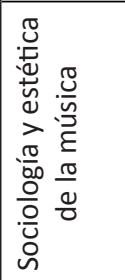 & 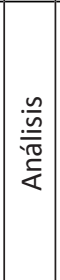 & 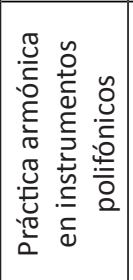 & ! & 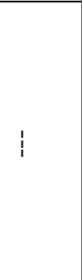 & 1 & 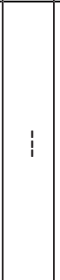 & : & : & : & 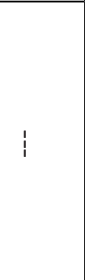 \\
\hline \multicolumn{12}{|c|}{ 亗 } & \multicolumn{2}{|c|}{ 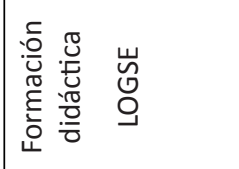 } \\
\hline
\end{tabular}




\begin{tabular}{|c|c|c|c|c|c|c|c|c|c|c|c|}
\hline 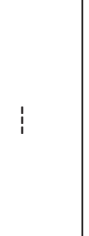 & 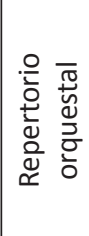 & 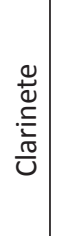 & : & 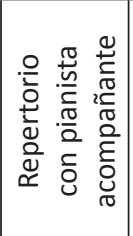 & 1 & 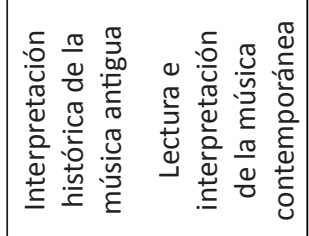 & 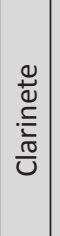 & 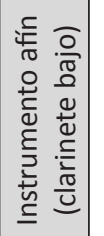 & 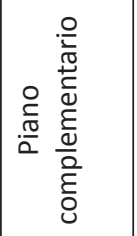 & 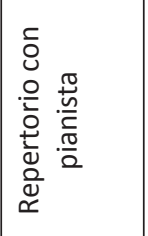 & 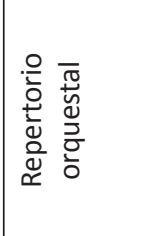 \\
\hline 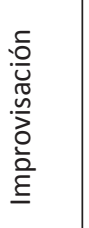 & 1 & 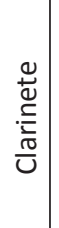 & 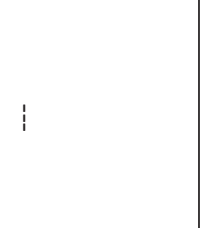 & 1 & 1 & 1 & 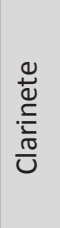 & & 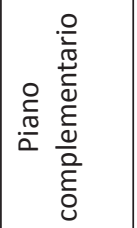 & 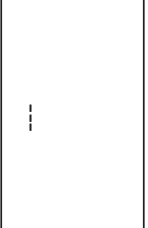 & 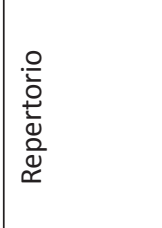 \\
\hline I & 1 & 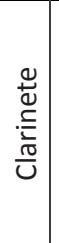 & ! & 1 & 1 & i & 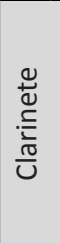 & & 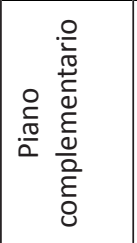 & 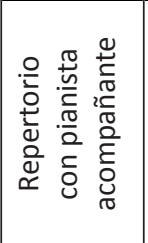 & 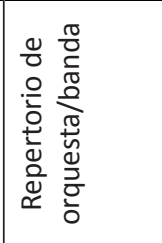 \\
\hline 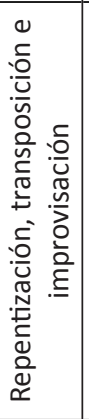 & 1 & 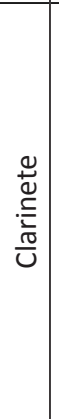 & : & 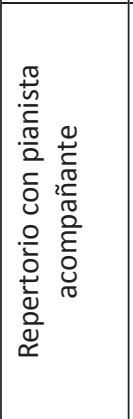 & 1 & 1 & 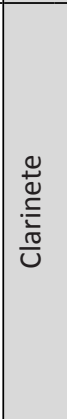 & & 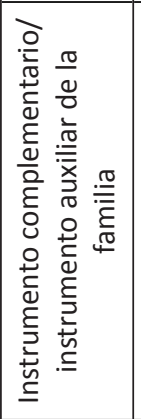 & 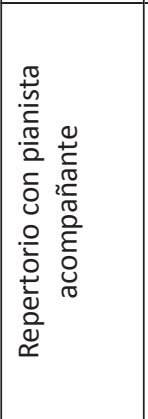 & 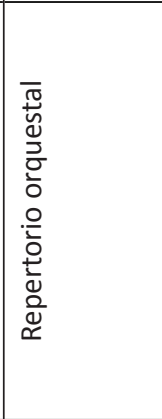 \\
\hline i & 1 & 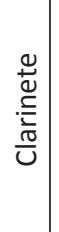 & : & 1 & 1 & 1 & 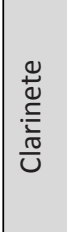 & & 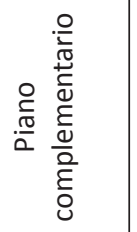 & 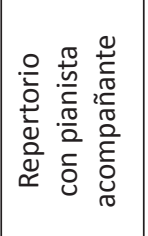 & 1 \\
\hline 1 & 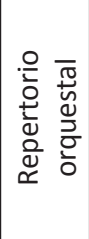 & 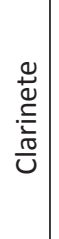 & 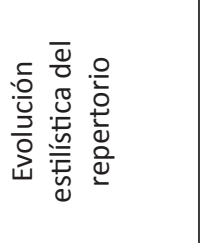 & 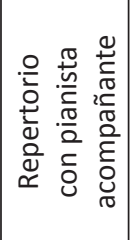 & 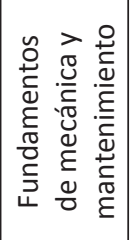 & 1 & 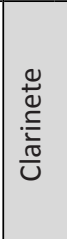 & & 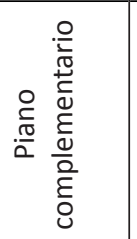 & 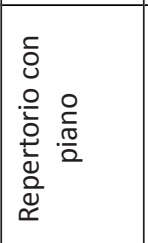 & 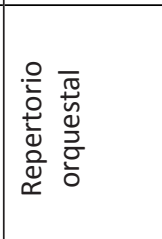 \\
\hline 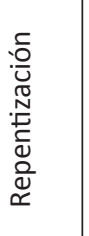 & 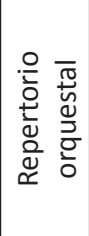 & 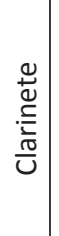 & 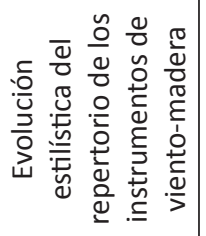 & 1 & $i$ & 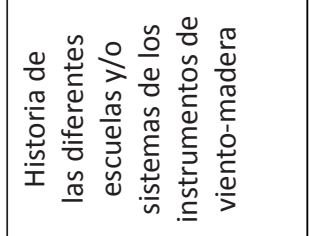 & 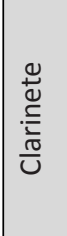 & & 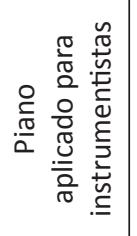 & 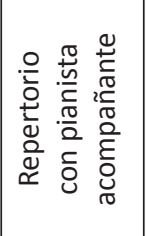 & 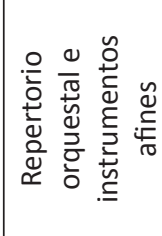 \\
\hline \multicolumn{12}{|c|}{ 亗 } \\
\hline
\end{tabular}




\begin{tabular}{|c|c|c|c|c|c|c|c|c|c|c|}
\hline 1 & 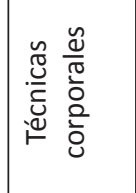 & 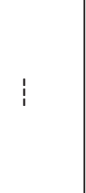 & 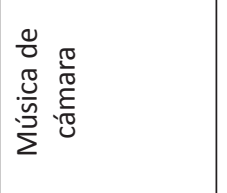 & 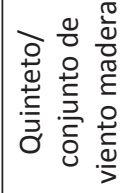 & 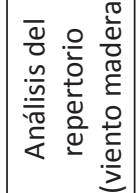 & 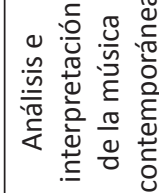 & & & 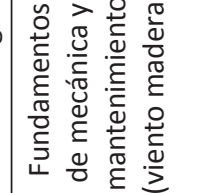 & $:$ \\
\hline : & 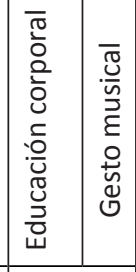 & 1 & 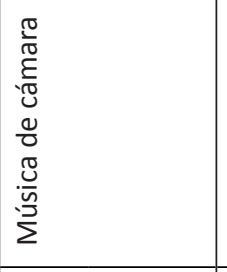 & 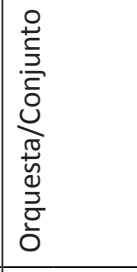 & : & 1 & ! & : & & : \\
\hline 1 & 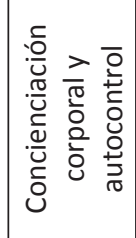 & & 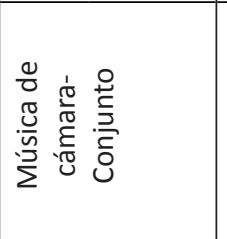 & 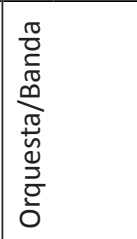 & 1 & 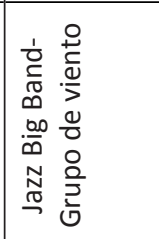 & i & : & 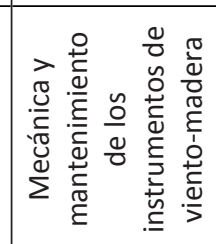 & 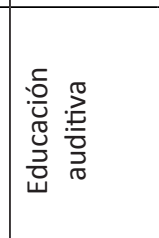 \\
\hline 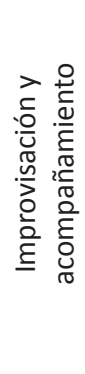 & & 1 & 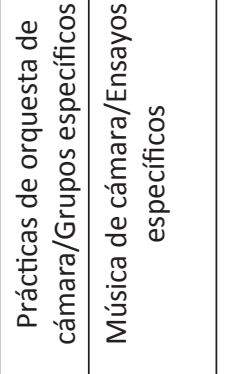 & 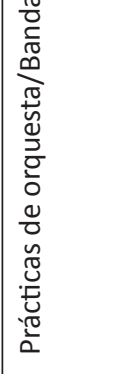 & 1 & 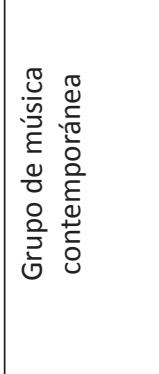 & 1 & : & & \\
\hline 1 & 1 & 1 & 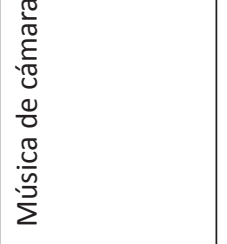 & 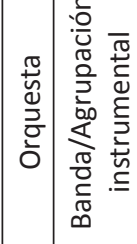 & 1 & 1 & $\frac{8}{3}$ & : & & \\
\hline 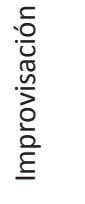 & 1 & 1 & 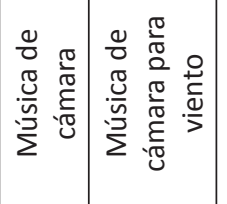 & 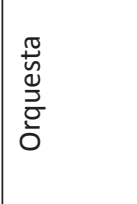 & 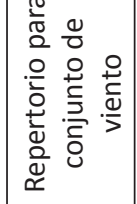 & 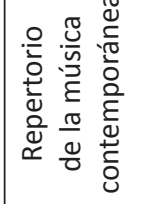 & & : & & 1 \\
\hline 1 & 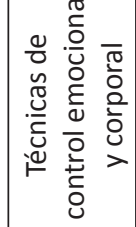 & 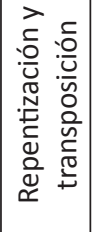 & 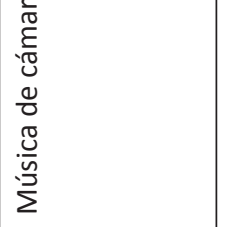 & 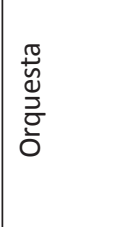 & : & 1 & & : & & $\mid$ \\
\hline & & & & & & & & & & 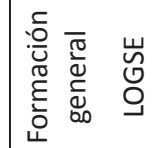 \\
\hline
\end{tabular}




\begin{tabular}{|c|c|c|c|c|c|c|c|c|c|c|c|c|c|c|c|}
\hline \multicolumn{2}{|c|}{ 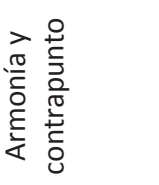 } & \multicolumn{2}{|c|}{ 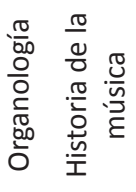 } & \multicolumn{2}{|l|}{ 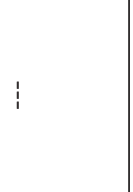 } & 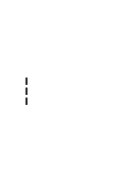 & 1 & 1 & ! & 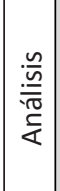 & 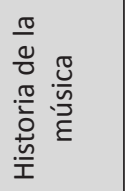 & 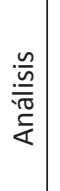 & 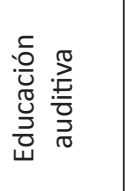 & 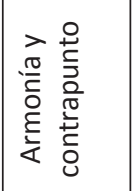 & I \\
\hline \multicolumn{2}{|c|}{ 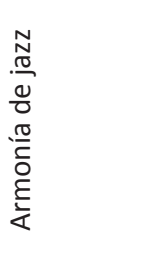 } & 1 & 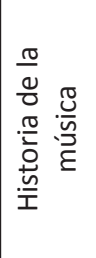 & 1 & & 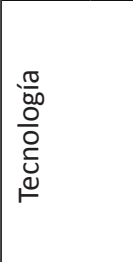 & 1 & 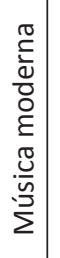 & : & 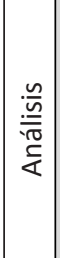 & 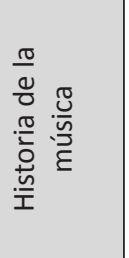 & $\frac{\sqrt[n]{5}}{\frac{5}{\bar{\pi}}}$ & 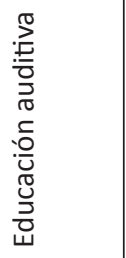 & 1 & 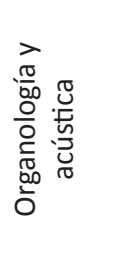 \\
\hline $\begin{array}{l}\frac{\pi}{\frac{\pi}{\sigma}} \\
\frac{\partial}{\xi} \\
\frac{\xi}{\alpha}\end{array}$ & $\begin{array}{l}\frac{2}{5} \\
\frac{2}{5} \\
\frac{2}{5} \\
0\end{array}$ & 1 & 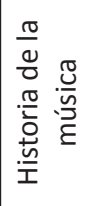 & 1 & & 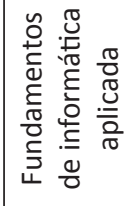 & 1 & 1 & i & 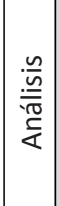 & 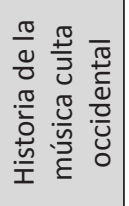 & 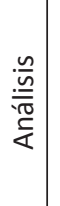 & 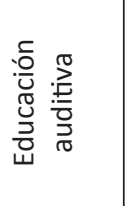 & 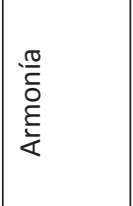 & : \\
\hline \multicolumn{2}{|c|}{ 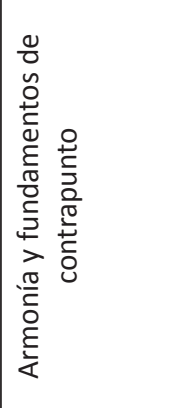 } & 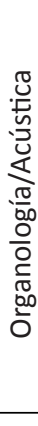 & 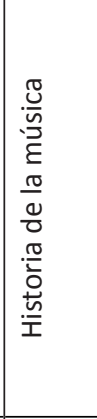 & \multicolumn{2}{|c|}{ 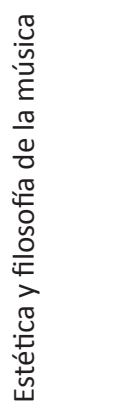 } & 1 & 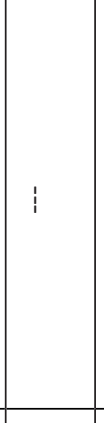 & i & : & \multicolumn{2}{|c|}{ 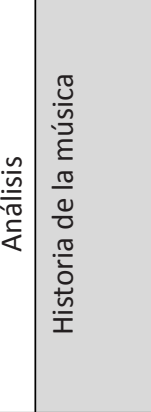 } & 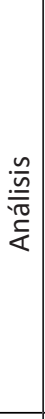 & 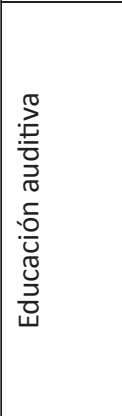 & 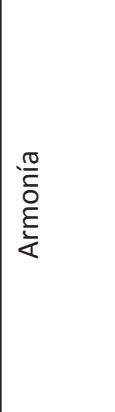 & 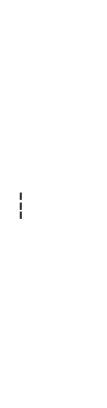 \\
\hline 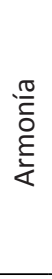 & 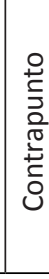 & 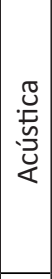 & 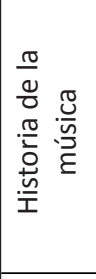 & 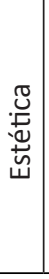 & 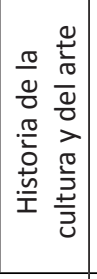 & 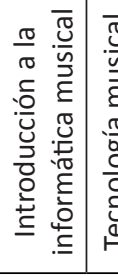 & 1 & 1 & i & 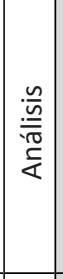 & 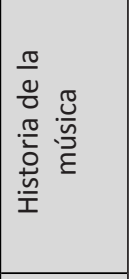 & 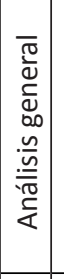 & 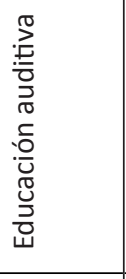 & 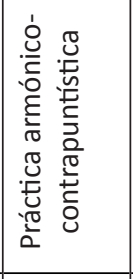 & 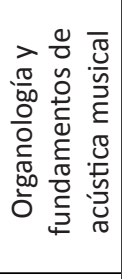 \\
\hline \multicolumn{2}{|c|}{ 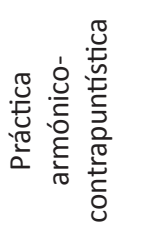 } & 1 & 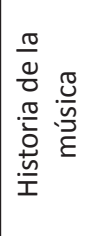 & \multicolumn{2}{|c|}{ 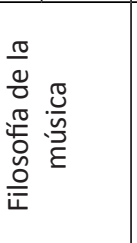 } & 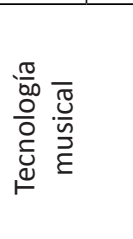 & 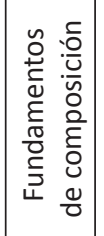 & 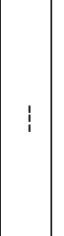 & 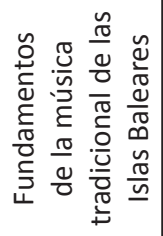 & 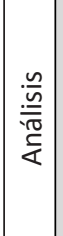 & 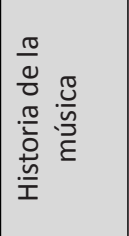 & 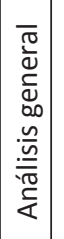 & i & 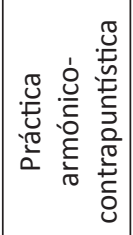 & 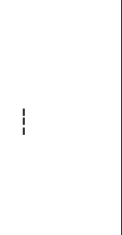 \\
\hline \multicolumn{2}{|c|}{ 兽 } & 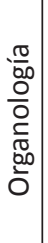 & 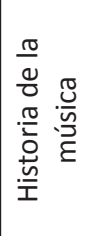 & \multicolumn{2}{|l|}{1} & I & 1 & 1 & 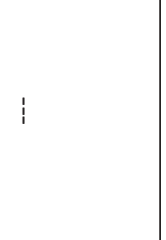 & \multicolumn{2}{|c|}{ 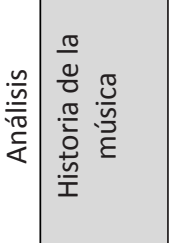 } & 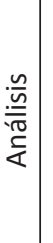 & 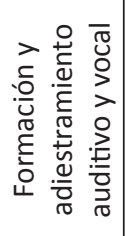 & 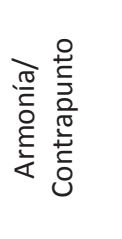 & $\begin{array}{l}\frac{\pi}{00} \\
\frac{0}{0} \\
\frac{0}{0} \\
\frac{0}{0} \\
00 \\
0\end{array}$ \\
\hline & & & & & & & & & & & 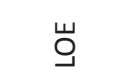 & & & & \\
\hline
\end{tabular}




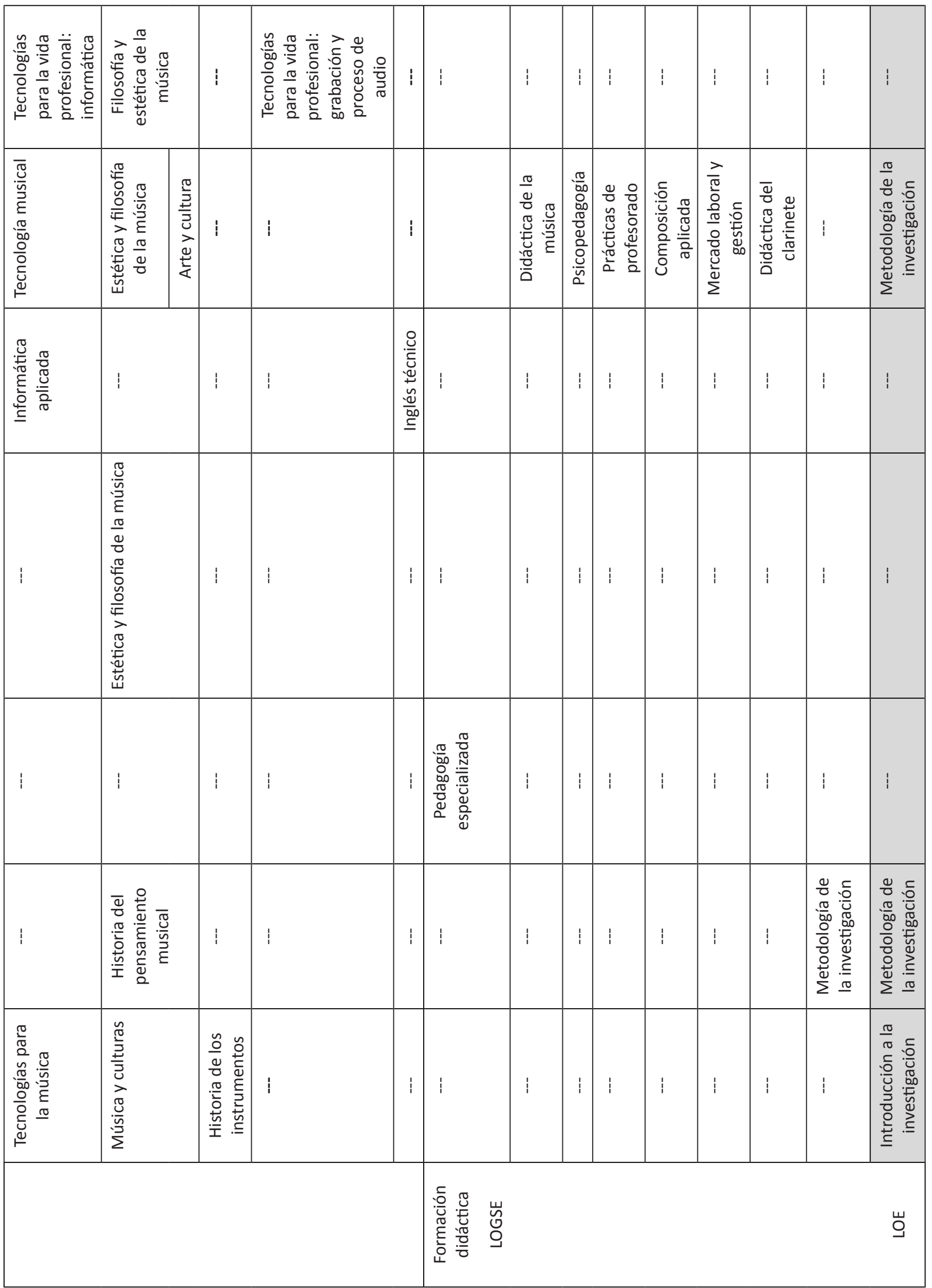



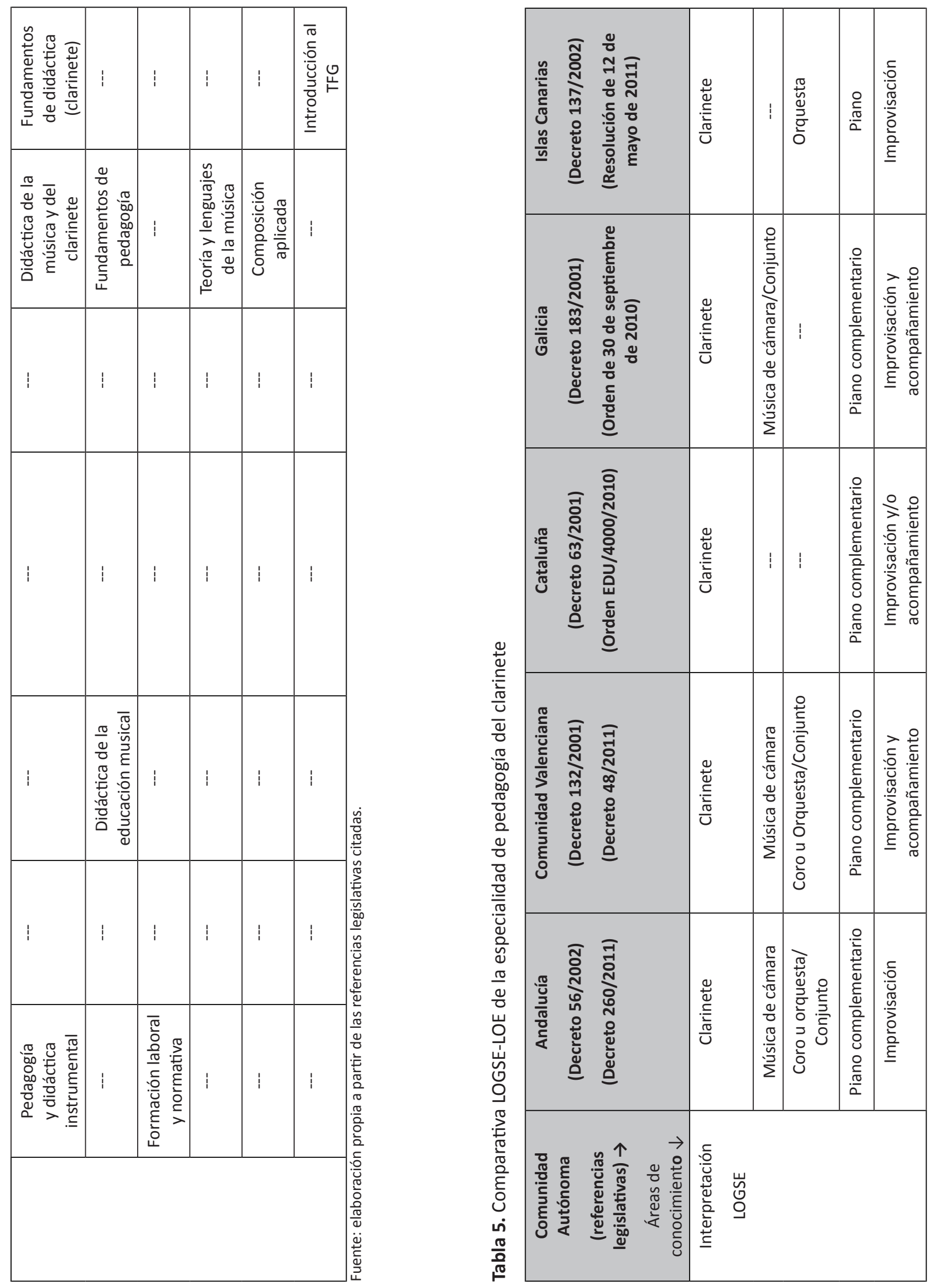


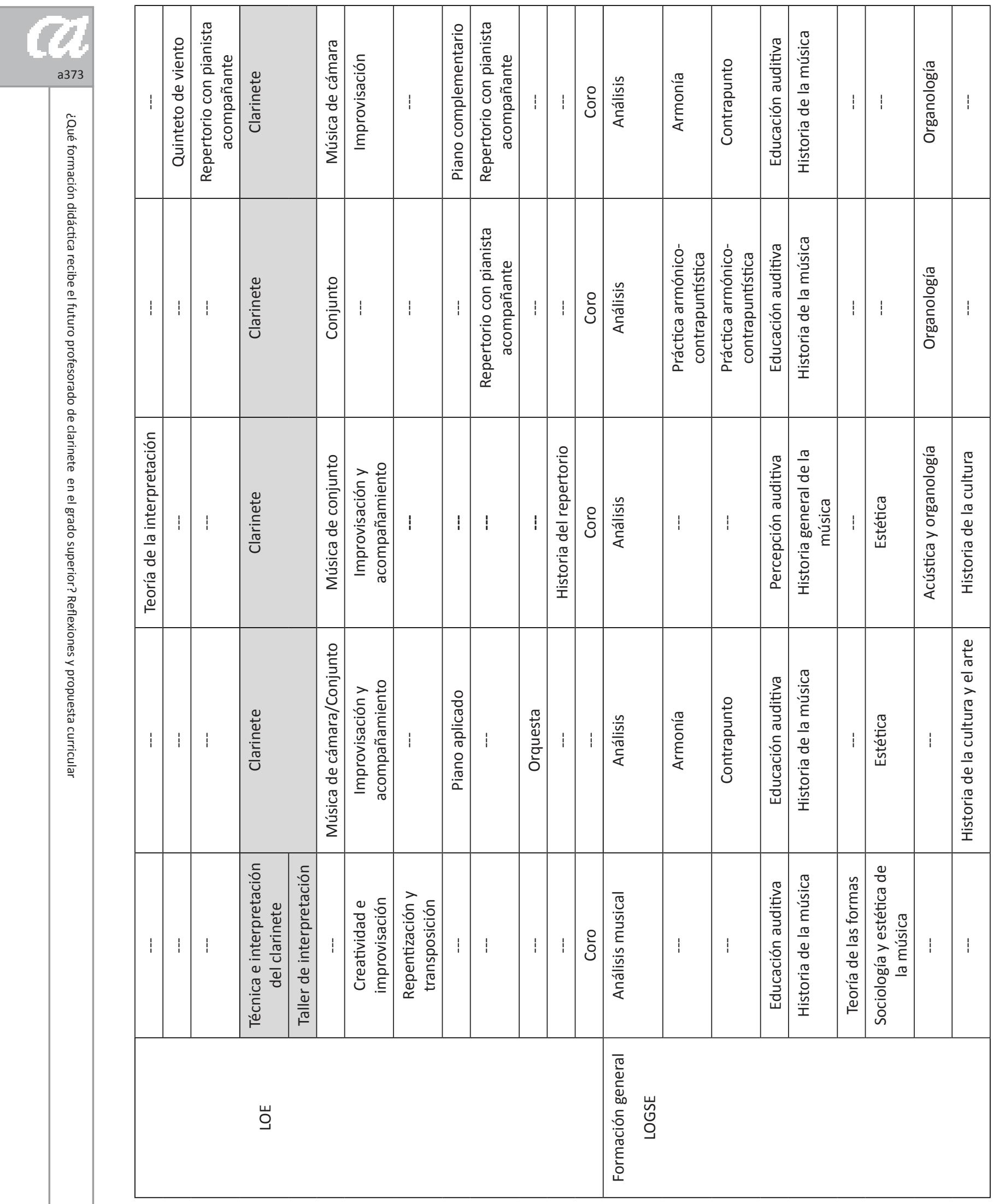




\begin{tabular}{|c|c|c|c|c|c|c|c|c|c|c|c|c|c|c|c|c|c|c|c|}
\hline I & I & 1 & 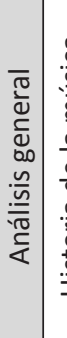 & 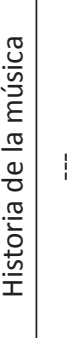 & 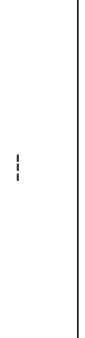 & 1 & 1 & 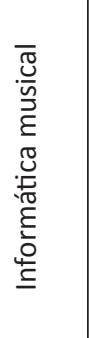 & 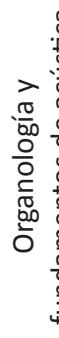 & 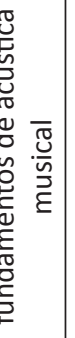 & 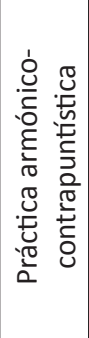 & 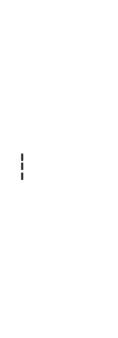 & 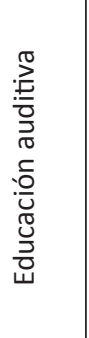 & 1 & 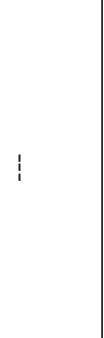 & 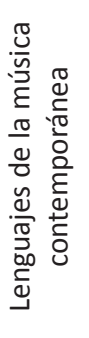 & 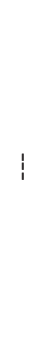 & & \\
\hline 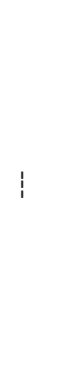 & 1 & $!$ & 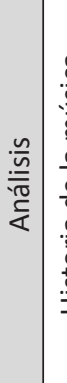 & 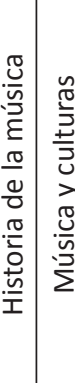 & 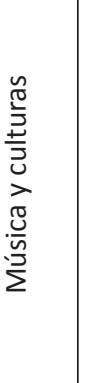 & 1 & 1 & 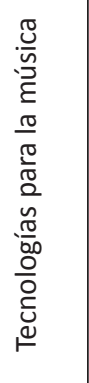 & $\begin{array}{l}\frac{\pi}{00} \\
\frac{0}{0} \\
\frac{0}{00} \\
0 \\
0\end{array}$ & 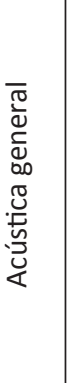 & 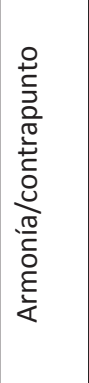 & i & 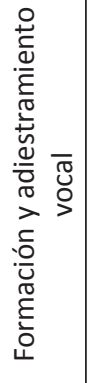 & 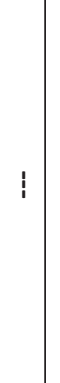 & 1 & 1 & 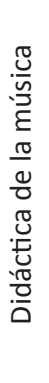 & & \\
\hline 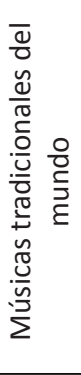 & 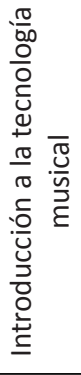 & 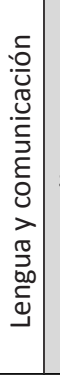 & 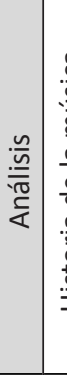 & 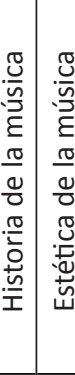 & 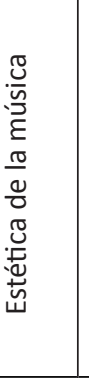 & 1 & 1 & 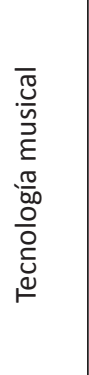 & : & & 1 & 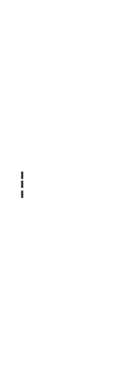 & $\begin{array}{l}\frac{0}{0} \\
\frac{0}{0} \\
\frac{0}{0} \\
: \frac{0}{0} \\
\frac{0}{0} \\
\stackrel{0}{0} \\
\frac{0}{4}\end{array}$ & 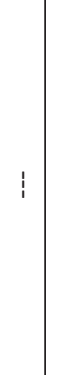 & 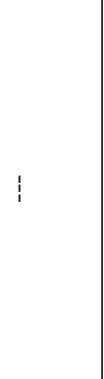 & 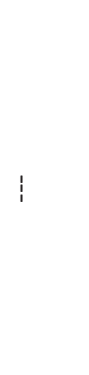 & $\begin{array}{l}\frac{\pi}{0} \\
\frac{0}{5} \\
\frac{\pi}{\varepsilon} \\
\frac{\pi}{0} \\
\frac{0}{0} \\
\frac{\pi}{00} \\
00 \\
\frac{\pi}{0} \\
\frac{\pi}{0} \\
0\end{array}$ & & 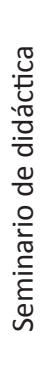 \\
\hline 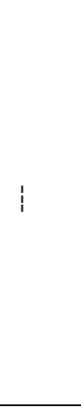 & 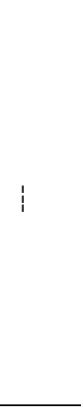 & 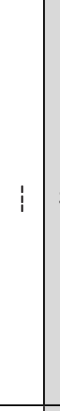 & $\begin{array}{l}\frac{n}{\frac{n}{\underline{n}}} \\
\frac{5}{4} \\
\frac{5}{4}\end{array}$ & 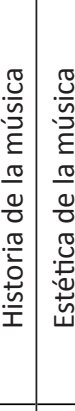 & 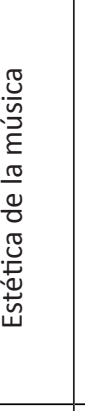 & 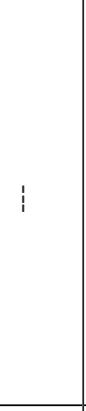 & $!$ & 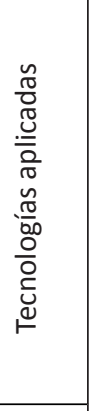 & 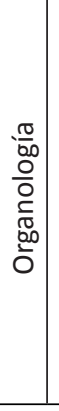 & 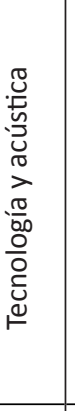 & 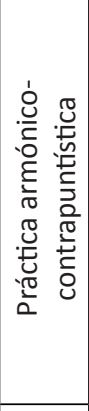 & I & 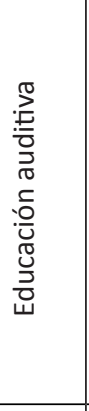 & 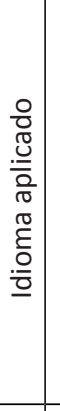 & 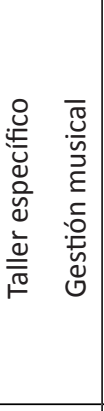 & 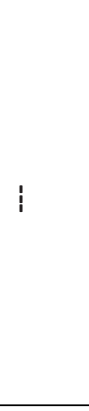 & 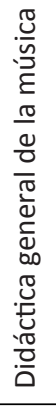 & & \\
\hline 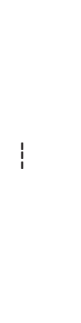 & 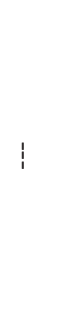 & 1 & 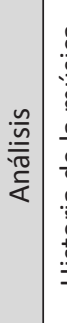 & 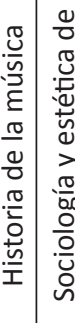 & 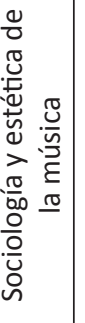 & 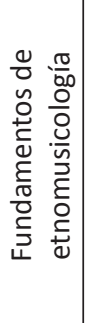 & $\mid$\begin{tabular}{|c|}
$\frac{N}{T}$ \\
$\frac{7}{0}$ \\
$\frac{0}{0}$ \\
$\frac{0}{0}$ \\
$\frac{0}{0}$ \\
$\frac{0}{0}$ \\
$\frac{0}{0}$ \\
1
\end{tabular} & 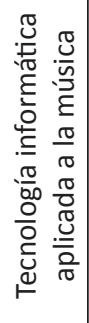 & 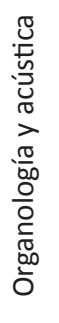 & & 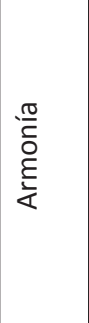 & 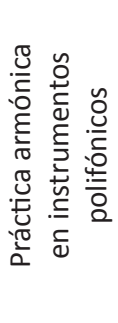 & : & 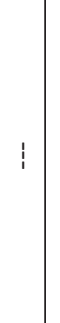 & 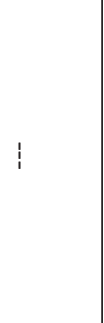 & 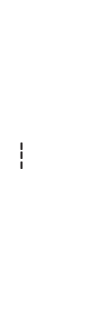 & 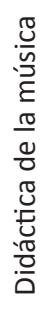 & & \\
\hline & & & 亗 & & & & & & & & & & & & & & 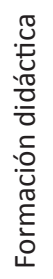 & $\begin{array}{l}\text { U్ } \\
\text { O }\end{array}$ & \\
\hline
\end{tabular}




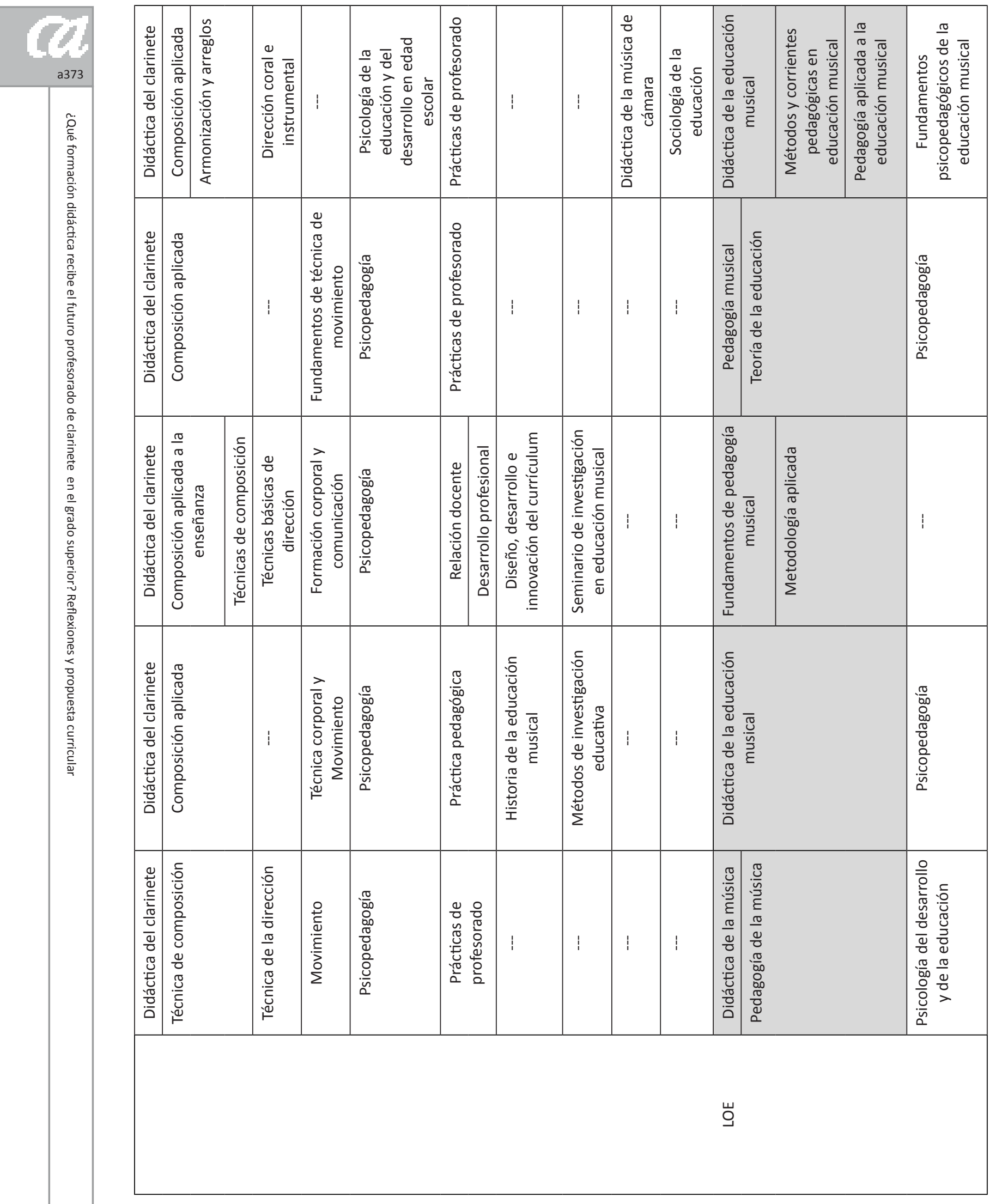




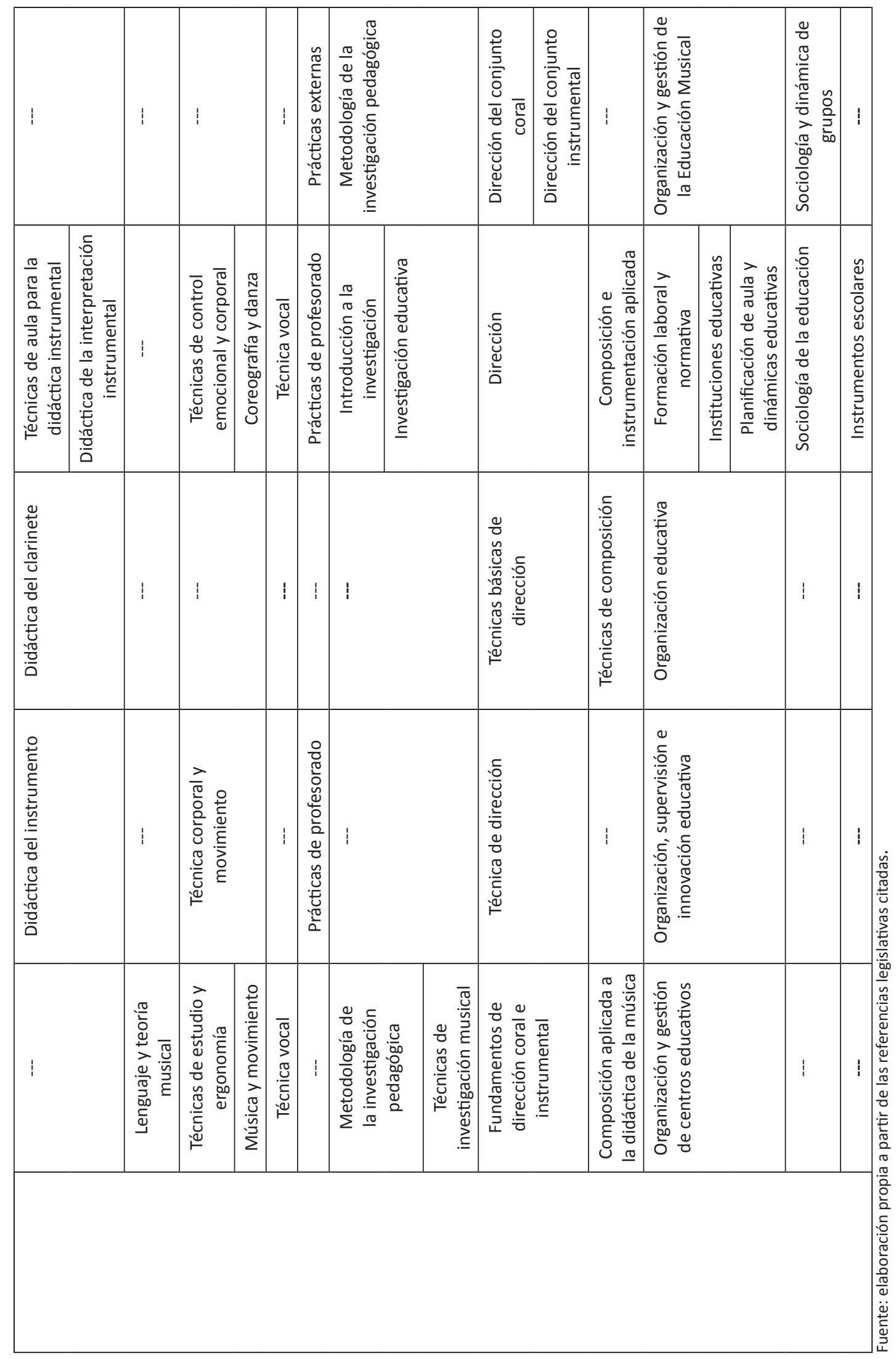


2.1. Título superior de música, especialidad clarinete versus título superior de música, especialidad pedagogía del clarinete

Andalucía, Comunidad Valenciana, Asturias, Canarias, Galicia y Navarra son las únicas comunidades que ofertaban la especialidad de pedagogía del clarinete. Estas comunidades contemplan los itinerarios de interpretación y de pedagogía; mientras otras optaban por la formación de interpretación. Curiosamente una importante parte de los titulados terminarán ejerciendo como docentes, tal como hemos argumentado anteriormente.

Resulta en cualquier caso sorprendente que no en todas las comunidades autónomas se recoja la posibilidad de estudiar una pedagogía instrumental específica: de aquellas que ofertan el doble itinerario (interpretación y pedagogía), algunas lo hacen con un contenido de materias concreto y austero (Cataluña y Valencia) y otras ofertan materias relacionadas con la pedagogía, si bien son materias de un espectro global (Asturias y Galicia, y Andalucía y Canarias), si bien no de forma tan dilatada. El tratamiento pedagógico del instrumento a través de contenidos exclusivos instrumentales se limita a la didáctica del mismo, que suele aparecer frecuentemente en todas las propuestas, pero orientada hacia contenidos generales. Otro grupo de materias son las relacionadas con los aspectos sociológicos y psicopedagógicos, que afectan a todas las especialidades. Resulta curioso el tratamiento a través de distintas asignaturas de los aspectos relacionados con la organización y gestión de centros. De modo que, independientemente de la amplitud y orientación de las materias específicas pedagógicas, existe el rasgo común de que están orientadas al concepto de pedagogía general, eludiendo cualquier contenido didáctico instrumental, aspecto que ya defendimos anteriormente y que prácticamente no aparece en ningún currículo.

\subsection{Salidas profesionales y realidad laboral}

Las salidas profesionales de un titulado en clarinete se han diversificado con la evolución de la legislación, a pesar de que los estudios muestran que la mayoría de los titulados se dedica a la docencia (Cid, 2012); aunque, también queda claro que el estudiantado no conoce sus otras opciones (Álvarez González), echándose en falta una orientación académico-laboral durante los estudios.

Quedan lejanos los planes de estudios de 1942 o de 1966, orientados hacia la interpretación y la docencia en conservatorios o en cualquier otro centro de ense- ñanza reglada. Sin embargo, y como si de una relación causa-efecto se tratase, puede existir una relación bilateral entre las necesidades y cambios en los hábitos sociales de los últimos años en nuestro país, con los cambios sustanciales en los planes de estudios (Ley Orgánica 1/1990, de 3 de octubre, de Ordenación General del Sistema Educativo (LOGSE), la todavía bisoña Ley Orgánica 2/2006, de 3 de mayo, de Educación (LOE), y la nueva Ley Orgánica 8/2013, de 9 de diciembre, para la mejora de la calidad educativa (LOMCE)).

La sociedad ha generado unas necesidades que deben ser atendidas, como no podía ser de otra manera, por profesionales cualificados. En este sentido los nuevos planes de estudios han supuesto numerosos cambios para los titulados. Los contenidos de estos planes aportan una formación más amplia y equilibrada, con materias como lenguaje musical, armonía, gestión y promoción cultural, por ejemplo. Una vez superado este escollo que suponía abordar desde el punto de vista académico y oficial todas las posibilidades de un estudiante de clarinete de formarse en otros ámbitos, el abanico de opciones para orientar un futuro profesional se ha incrementado ligeramente. Principalmente, podríamos establecer tres ámbitos principales: la interpretación, la docencia y la gestión/promoción cultural.

La opción de freelance o músico independiente y libre es prácticamente irreal y utópica en España, ya que resulta difícil, habida cuenta de la poca actividad musical en el ámbito nacional.

La interpretación en bandas y orquestas profesionales era una opción muy deseada hasta la última década del pasado siglo XX. En relación a este sector, habría que hacer dos variantes claramente diferenciadas: bandas militares y bandas civiles. La oferta laboral en el ejército ha caído en volumen en los últimos años por la reagrupación de algunas unidades, con lo que se han reducido las formaciones y expectativas; aunque, claro, esta posibilidad siempre quedó para aquellos instrumentistas que más destacaron en sus estudios (Álvarez González). Y en cuanto a las bandas municipales, sigue siendo una interesante opción porque en nuestro país existe un número considerable de bandas dependientes de los ayuntamientos. Es cierto que la oferta de vacantes orquestales de clarinete es muy inferior, pero esta opción goza de un importante prestigio.

Y por último, la docencia. Sin duda es la opción más realista para acceder al mercado laboral, ya que los titulados son conscientes de que optar por la ense- 
ñanza es un medio mucho más seguro; de hecho, Álvarez González señala que el alumnado ve la docencia como profesión y la interpretación como un complemento que les permite disfrutar de lo que más les gusta. La difusión de la música en la sociedad como una realidad necesaria para el desarrollo cultural de la misma ha permitido que en las últimas décadas la administración y la propia iniciativa privada favorezcan la creación de numerosos conservatorios, escuelas municipales y academias. La Enseñanza Secundaria Obligatoria era una opción muy adecuada, que ha terminado por casi desaparecer gracias a reformas educativas como las promovidas por la LOMCE, que reduce las horas de música todavía más.

\section{PROPUESTAS DE MEJORA A MODO DE CONCLUSIÓN}

Sería poco razonable establecer una tribuna reivindicativa a favor de la importancia en la formación pedagógica de los clarinetistas, una línea roja que separase el estudio del clarinete orientado a la práctica instrumental respecto al enfocado hacia la enseñanza, porque sin duda hay muchos más aspectos relacionados e inseparables. No se puede obviar que, como comenta Palacios (1998), el profesor de instrumento además de ser un técnico debería ser un maestro, para así poder responder adecuadamente a la situación laboral que le espera al terminar sus estudios.

En el aula de clarinete, hasta ahora siempre había sido suficiente con el interés del docente por la didáctica (cursos de formación, seminarios), a la hora de poder atender adecuadamente a su alumnado, tal como comentamos en epígrafes anteriores. Pero sin duda, con la promoción de las reformas educativas que mostraban al alumnado el sentido y significado artístico de la interpretación musical (Pozo, Bautista y Torrado, 2002), estamos ante una oportunidad de mejorar un sistema cuyas lagunas han sido siempre cubiertas con improvisación, dedicación, etc. Cid (2012) muestra en su investigación que el alumnado reclama una mayor atención a la formación pedagógica porque será a lo que se dediquen la gran mayoría.

Resulta difícil, si no imposible, disociar las materias específicas del ámbito clarinetístico y las materias de carácter más general relacionadas con la didáctica del clarinete (o generales). Muchos de los contenidos de ambos espectros se solaparían existiendo relaciones. El principal hecho diferencial de las asignaturas con una relación pedagógica asociada al clarinete específicamente y aquellas que estando vinculadas a él podrían ser útiles en cualquier especialidad didáctica instrumental o no instrumental serían las relacionadas con la historia, la morfología y la metodología, principalmente.

El conocimiento de la historia del instrumento es sin duda una herramienta necesaria para abordar la enseñanza instrumental. Conocer sus características, virtudes y defectos, será determinante para la interpretación que deberán ser reflejadas en la dirección del repertorio del alumno. Por otra parte, el conocimiento del instrumento ofrecerá importantes recursos para solucionar problemas en el aula. El profesor debe conocer la relación entre la morfología física de cada estudiante, las características morfológicas del material y saber asociarlas eficazmente. De hecho, entre las atribuciones del futuro docente de clarinete debería estar el conocimiento de que no existe una única técnica para cada instrumento, porque esto supondría obviar las diferencias individuales del alumnado (Jorquera, 2002).

La metodología específica del clarinete será una de las propuestas irrenunciables. Conocer los diferentes sistemas históricos como el método Romero que surgió para responder a las necesidades del clarinete mejorado por Antonio Romero (Rubio, 2016), las principales apuestas bibliográficas más actualizadas, y la planificación de los tiempos en los contenidos serán sin duda aspectos que deberán ser desarrollados. Siempre teniendo en cuenta que, en lo que se refiere a la didáctica instrumental, la "tradición" se remontaría a los métodos de estudio (método comprendido como manual de estudio) del siglo XIX que surgían de acuerdo con las necesidades técnicas del alumnado de la época (y de las características del instrumento) (Jorquera, 2002).

El estudio de la metodología estaría vinculado directamente a algo paralelo como es la didáctica específica del clarinete, que trataría sobre el modo más conveniente de ir resolviendo todos aquellos problemas que vayan surgiendo en el alumnado en función de un sinfín de circunstancias. Pero estudiar la didáctica específica del clarinete no es tan fácil, puesto que se carece de metodologías, que no de métodos de estudio; así Rubio (2013) destaca que ya en el siglo XIX especialistas del clarinete como Romero se quejaban de la falta de métodos (de estudio) para la formación instrumental y digamos que, por extensión, docente. En esta dirección, Bautista y Pérez-Echeverría (2008) consideran que las distintas reformas legislativas han llevado al profesor de instrumento a ampliar sus funciones, que pasaron de enseñar a ejecutar obras a capacitar al alumnado para comprenderlas, sentirlas e interpretarlas artísticamente: ahora la partitura es 
una herramienta de conocimiento y no solo el objeto de registro que fue antes de la LOGSE (Pozo, Bautista y Torrado, 2008).

No podemos dejar de lado la historia de la literatura clarinetística, enfocada al conocimiento general de sus posibilidades didácticas y su distribución para las diferentes etapas educativas, además de como fuente de recursos didácticos. La literatura del clarinete se remonta a esos libros de ejercicios técnicos que terminarían transformándose en fines en sí mismos (estudio técnico exclusivo), descontextualizándose de lo que fueron inicialmente (Jorquera, 2002); no obstante, es necesario que se conozca esta evolución para enfocar mejor la práctica docente.

Otras asignaturas que serían un excelente complemento son la composición y la dirección aplicada, que formarían al futuro docente para elaborar materiales didácticos, técnicos y musicales, y para organizar, planificar y rentabilizar cualquier formación instrumental. Así, se estaría respondiendo a otra realidad laboral: los grupos de cámara u otro tipo de agrupaciones que pueden llegar a contar con ayudas de ayuntamientos (Álvarez González).

Con todo, y dada la situación real de los estudios de grado superior de clarinete (o, para ser legalmente correctos, título superior de música, especialidad clarinete), ya comentada por Cid (2012), que recoge las consideraciones del alumnado y del profesorado en relación a que forman solistas y no docentes, en clara contradicción con la realidad laboral, desde este artí- culo defendemos la consolidación de dos itinerarios diferentes: uno pedagógico y otro interpretativo, pero relacionados. La especialidad de pedagogía no puede renunciar a una formación instrumental de calidad, ni el itinerario de interpretación debe desarrollarse sin tener en cuenta la pedagogía. Ambos deben aprender a desarrollar herramientas comunicativas y relacionales para formar adecuadamente a sus estudiantes (Jorquera, 2002). Sería igualmente desafortunado el hecho de que la figura de un músico, que tenga grandes virtudes para la comunicación en el escenario pero no sepa transmitir sus conocimientos de manera ordenada, acabara siendo profesor; así como resulta imposible que alguien que posea capacidad y buenas maneras para enseñar parta de la premisa conformista de no dominar desde un punto de vista práctico la materia que ha de impartir. Es decir, que habría que comenzar a olvidar la tradición habitual de los conservatorios de música de considerar que la musicalidad del intérprete ni se enseña ni se aprende (Bautista y Pérez-Echeverría, 2008), puesto que habría que enseñar a ejecutarla a partir del análisis estilístico, formal y armónico, desde el aula de instrumento.

Después de todo lo expuesto, resulta lícito afirmar que tendría que reestructurarse la especialidad para que responda a la realidad profesional musical, de forma que se pudiese paliar el déficit pedagógico de la enseñanza musical en los conservatorios al que ya aludía Pliego de Andrés en Los conservatorios de música en el proyecto de Ley Orgánica de Educación y que, a fecha de hoy, sigue estando presente.

\section{BIBLIOGRAFÍA}

Bautista, A. y Pérez-Echeverría, M. P. (2008). ¿Qué consideran los profesores de instrumento que deben enseñar en sus clases? Cultura y Educación, 20, 1, pp. 17-34. https://doi. org/10.1174/113564008783781477

Bernabé, M. M. (2013). Formación didáctica en enseñanzas elementales de clarinete. Música y Educación, 93, 1, pp. 70-90.

Cabrera, R. (2009). El calentamiento como propuesta didáctica para $1^{\mathrm{er}}$ curso de Enseñanzas Profesionales en la especialidad de Clarinete. Revista Digital Ciencia y Didáctica, 27, pp. 32-41.

Cid, M. J. (2012). Los conservatorios superiores de Galicia durante la LOGSE. Revista Electrónica de LEEME. Lista
Electrónica Europea de Música en la Educación, 29, pp. 1-22.

Holgado, F. P., Navas, L. y Marco, V. (2013). The Students' Academic Performance at the Conservatory of Music: A Structural Model from the Motivational Variables. Revista de Psicodidáctica, 18, 2, pp. 257-273. https://doi.org/10.1387/RevPsicodidact.6942

Jorquera, C. (2002). ¿Existe una didáctica del instrumento musical? Revista Electrónica de LEEME. Lista Electrónica Europea de Música en la Educación, 9, pp. 1-12.

Muñoz Muñoz, A. (2009). El clarinete: didáctica y metodología. Revista Digital Innovación y Experiencias Educativas, 22, pp. 1-9.
Nuño Guerrero, I. (2010). La investigación en las enseñanzas musicales. Revista Digital Innovación y Experiencias Educativas, 28, pp. 1-12.

Orlandini, L. (2012). La interpretación musical. Revista Musical Chilena, 218, pp. 77-81. https://doi.org/10.4067/S071627902012000200006

Palacios, M. (1998). La didáctica aplicada a la enseñanza del instrumento. Revista Electrónica de LEEME. Lista Electrónica Europea de Música en la Educación, 2, pp. 1-7.

Pozo, J. I., Bautista, A. y Torrado, J. A. (2008). El aprendizaje y la enseñanza de la interpretación musical: cambiando las concepciones y las prácticas. Cultura y Educación, 20, 1, pp. 5-15. https://doi. org/10.1174/113564008783781495 
Roldán Alcázar, M. M. (2010). Análisis de los métodos para la enseñanza del piano en los primeros niveles. Hekademos: revista educativa digital, 7, pp. 133-150.

Rubio, P. (2013). El Conservatorio de Madrid y el método de clarinete de Antonio Romero. Música. Revista del Real Conservatorio Superior de Música de Madrid, 20, pp. 13-37.

Rubio, P. (2016). El clarinete Sistema Romero. Instrumento oficial para la enseñanza del clarinete en el Real Conservatorio de Música y Declamación. Música. Revista del Real Conservatorio Superior de Música de Madrid, 23, pp. 45-80.

Veintimilla, A. (2010). Las enseñanzas musicales en el EEES. En Vico, M. L. (coord.). Las Enseñanzas Artísticas Superiores en el Espacio Europeo de Educación Superior. Madrid: Ministerio de Educación, pp. 115-160.

Zaldívar, A. (2005). Las enseñanzas musicales y el nuevo Espacio Europeo de Educación Superior: el reto de un marco organizativo adecuado y la necesidad de la investigación creativa y "performativa". Revista Interuniversitaria de Formación de Profesorado, 19, 1, pp. 95-122.

\section{Textos legales}

Declaración de Bolonia (1999). Recuperado de http://www.educacion.gob.es/boloniaensecundaria/img/Declaracion_Bolonia.pdf

Decreto 2618/1966, de 10 de septiembre, sobre Reglamentación general de los Conservatorios de Música. Boletín Oficial del Estado del 24 de octubre de 1966, no 254, referencia 20845, pp. 13381-13387.

Decreto 63/2001, de 20 de febrero, por el cual se establece la ordenación curricular del grado superior de las enseñanzas de música y se regula la prueba de acceso a estos estudios. Diari Oficial de la Generalitat de Catalunya del 05 de marzo de 2001, no 3340, pp. 3063-3123.

Decreto 73/2001, de 24 de abril, de implantación en la Comunidad Autónoma del País Vasco de los estudios superiores de Música de acuerdo con la Ley de Ordenación General del Sistema Educativo. Euskal Herriko Agintaritzaren Aldizkaria del 08 de mayo de 2001, no 86, referencia 2351, pp. 9031-9033.

Decreto 183/2001, de 19 de julio, por el que se establece el currículo de grado superior de las enseñanzas de música y el acceso a dicho grado. Diario Oficial de Galicia del 13 de agosto de 2001, no 156, pp. 10892-10919.

Decreto 132/2001, de 26 de julio 2001, del Gobierno Valenciano, por el que se establece el currículo del grado superior de música en la Comunidad Valenciana y el acceso a dichas enseñanzas. Diari Oficial de la Generalitat Valenciana del 14 de agosto de 2001, no 4064, referencia X8200, pp. 18132-18170.

Decreto 56/2002, de 19 de febrero, por el que se establece el currículo del Grado Superior en las Enseñanzas de Música en los Conservatorios de Andalucía. Boletín Oficial de la Junta de Andalucía del 5 de marzo de 2002, nㅇ 27, pp. 3461-3491.

Decreto 137/2002, de 23 de septiembre, por el que se crea el Conservatorio Superior de Música de Canarias. Boletín Oficial de Canarias del 18 de octubre de 2002, no 139 , referencia 1496, pp. 17053-17058.

Decreto 36/2010, de 2 de junio, del Consejo de Gobierno, por el que se establece el Plan de Estudios para la Comunidad de Madrid, de las enseñanzas artísticas superiores de Grado en Música. Boletín Oficial de la Comunidad de Madrid del 16 de junio de 2010, no 141, referencia 1, pp. 11-253.

Decreto 48/2011, de 6 de mayo, del Consell, por el que se establece la ordenación de las enseñanzas artísticas superiores y se determina el marco normativo para la implantación de los planes de estudios correspondientes a los títulos oficiales de graduado o graduada en las diferentes enseñanzas artísticas superiores, en el ámbito de la Comunitat Valenciana. Diari Oficial de la Generalitat Valenciana del 10 de mayo de 2011, no 6517, referencia 5272, pp. 18092-18101.

Decreto 260/2011, de 26 de julio, por el que se establecen las enseñanzas artísticas superiores de Grado en Música en Andalucía. Boletín Oficial de la Junta de Andalucía del 23 de agosto de 2011, no 165, pp. 37-92.

Decreto 57/2011, de 15 de septiembre, por el que se establece el Plan de Estudios de las Especialidades de Composición, Interpretación y Musicología, de las Enseñanzas Artísticas Superiores de Grado en Música en la Comunidad de Castilla y León. Boletín Oficial de Castilla y León de 21 de septiembre de 2011, no 183, referencia 21092011-3, pp. 72617-72823.
Decreto 28/2014, de 4 de marzo, por el que se establece en la Comunidad Autónoma de Extremadura el plan de estudios de las enseñanzas artísticas superiores de Música reguladas por la Ley Orgánica 2/2006, de 3 de mayo, de Educación. Diario Oficial de Extremadura del 10 de marzo de 2014, no 47, pp. 7167-7307.

Ley Orgánica 1/1990, de 3 de octubre, de Ordenación General del Sistema Educativo. Boletín Oficial del Estado del 4 de octubre de 1990, no 238, referencia 24172, pp. 28927-28942.

Ley Orgánica 10/2002, de 23 de diciembre, de Calidad de la Educación. Boletín Oficial del Estado del 24 de diciembre de 2002, no 307, referencia 25037, pp. 45188-45220.

Ley Orgánica 2/2006, de 3 de mayo, de Educación. Boletín Oficial del Estado del 4 de mayo de 2006, no 106, referencia 7899, pp. $17158-17207$

Ley Orgánica 8/2013, de 9 de diciembre, para la mejora de la calidad educativa. Boletín Oficial del Estado del 10 de diciembre de 2013, no 295, referencia 12886, pp. $97858-97921$.

Orden de 25 de junio de 1999 por la que se establece el currículo del grado superior de las enseñanzas de Música. Boletín Oficial del Estado del 3 de julio de 1999, no 158, referencia 14767, pp. 25473-25504.

Orden 1754/2001, de 11 de mayo, del Consejero de Educación, por la que se establece el currículo del grado superior de las enseñanzas de Música. Boletín Oficial de la Comunidad de Madrid del 22 de mayo de 2001, no 120, pp. 6-80.

Orden de 22 de noviembre de 2001 por la que se establece el currículo del grado superior de las enseñanzas de música y se regula la prueba de acceso a dicho grado en la Región de Murcia. Boletín Oficial de la Región de Murcia del 18 de diciembre de 2001, no 291, referencia 12756, pp. 16061-16104.

Orden de 16 de julio de 2002, por la que se aprueba el plan de estudios de las enseñanzas del Grado Superior de Música del Conservatorio Superior de Música Manuel Castillo, de Sevilla. Boletín Oficial de la Junta de Andalucía del 22 de agosto de 2002, no 98, p. 16475.

Orden de 16 de julio de 2002, por la que se aprueba el plan de estudios de las enseñanzas del Grado Superior de Música del Conservatorio Superior de Música 
Rafael Orozco, de Córdoba. Boletín Oficial de la Junta de Andalucía de 22 de agosto de 2002, no 98, p. 16476.

Orden de 16 de julio de 2002, por la que se aprueba el plan de estudios de las enseñanzas del Grado Superior de Música del Conservatorio Superior de Música Victoria Eugenia, de Granada. Boletín Oficial de la Junta de Andalucía de 22 de agosto de 2002, no 98, p. 16476.

Orden de 6 de mayo de 2003, del Departamento de Educación y Ciencia, por la que se adecuan algunos aspectos del currículo de grado superior de las enseñanzas musicales conforme a la nueva ordenación del sistema educativo en la Comunidad Autónoma de Aragón. Boletín Oficial de Aragón del 26 de mayo de 2003, no 63, referencia 1479, pp. 6388-6402.

Orden EDU/4000/2010, de 13 de desembre, per la qual s'aprova, amb carácter transitori, el pla d'estudis de grau dels ensenyaments artístics superiors de música del centre autoritzat de grau superior de música Liceu. Diari Oficial de la Generalitat de Catalunya del 21 de diciembre de 2010, no 5779, pp. 92246-92254.

Orden de 30 de septiembre de 2010 por la que se establece el plan de estudios de las enseñanzas artísticas superiores de grado en música en la Comunidad Autónoma de Galicia y se regula el acceso a dicho grado. Diario Oficial de Galicia del 8 de octubre de 2010, no 195, pp. 16943-16959.

Orden de 20 de agosto de 2011, del Departamento de Educación y Ciencia, por la que se establecen aspectos generales del currículum del Grado Superior en las enseñanzas musicales conforme a la nueva ordenación del sistema educativo y se determina con carácter experimental el desarrollo curricular del primer curso de esas enseñanzas en la Comunidad Autónoma de Aragón. Boletín Oficial de Aragón del 7 de septiembre de 2011, no 106, referencia 2221, pp. 6706-6723.

Orden Foral 110/2010, de 1 de julio, del Consejero de Educación, por la que se establece el plan de estudios de las enseñanzas superiores de música en el marco del Espacio Europeo de Educación Superior en la Comunidad Foral de Navarra. Boletín Oficial de Navarra del 23 de julio de 2010, no 89.

Ordre del conceller d'Educació i Cultura, d'1 de setembre de 2003, per la qual s'estableixen aspectos generals del currículum del grau superior dels en- senyaments de música i es determina, amb carácter experimental, el desenvolupament curricular dels cursos que comprenen aquests ensenyaments a la comunitata autónoma de les Illes Balears. Butlletí Oficial de les Illes Balears del 16 de septiembre de 2003, no 130, referencia 16768 , pp. 7-24.

Real Decreto 617/1995, de 21 de abril, por el que se establece los aspectos básicos del currículo del grado superior de las enseñanzas de Música y se regula la prueba de acceso a estos estudios. Boletín Oficial del Estado del 6 de junio de $1995, \mathrm{n}$ ㅇ 134, referencia 13594, pp. 16607-16631.

Real Decreto 1542/1994, de 8 de julio, por el que se establece las equivalencias entre los títulos de Música anteriores a la Ley Orgánica $1 / 1990$, de 3 de octubre, de Ordenación General del Sistema Educativo, y los establecidos en dicha ley. Boletín Oficial del Estado del 9 de agosto de 1994, no 189, referencia 18620, pp. 25538-25539.

Real Decreto 1614/2009, de 26 de octubre, por el que se establece la ordenación de las enseñanzas artísticas superiores reguladas por la Ley Orgánica 2/2006, de 3 de mayo, de Educación. Boletín Oficial del Estado del 27 de febrero de 2009, n 259, referencia 17005, pp. 89743-89752.

Real Decreto 631/2010, de 14 de mayo, por el que se regula el contenido básico de las enseñanzas artísticas superiores de Grado en Música establecidas en la Ley Orgánica 2/2006, de 3 de mayo, de Educación. Boletín Oficial del Estado del 5 de junio de 2010, no 137 , referencia 8955 , pp. $48480-48500$.

Resolució del director general de Cultura per la qual es sotmet a información pública l'avantprojecte de Decret pel qual s'estableix el pla d'estudis d'ensenyaments artístics superiors conduents al Títol Superior de Música en les especialitats de composició, interpretació (en les modalitats de corda, vent, percussió, saxòfon, piano, guitarra i veu), musicologia i pedagogia a les Illes Balears, i se'n regula l'avaluació. Butlletí Oficial de les Illes Balears del 15 de noviembre de 2014, no 157, referencia 20232, p. 52157.

Resolución de 1 de marzo de 2001, de la Consejería de Educación y Cultura, por la que se implanta el nuevo Grado Superior de las enseñanzas de música y se regula la prueba de acceso a dicho grado. Boletín Oficial del Principado de Asturias de 12 de marzo de 2001, n 59, pp. 2945-2947.

Resolución de 9 de julio de 2010, de la Consejería de Educación y Ciencia, por la que se establecen los planes de estudios de las enseñanzas artísticas superiores de Grado en Música impartidas en el Conservatorio Superior de Música “Eduardo Martínez Torner" de Oviedo, reguladas por la Ley Orgánica 2/2006, de 3 de mayo, de Educación. Boletín Oficial del Principado de Asturias de 27 de julio de 2010, no 173, pp. 1-11.

Resolución de 12 de mayo de 2011, por la que se corrige el error de hecho detectado, por omisión, en la publicación de la Orden de 29 de abril de 2011, que aprueba, con carácter experimental, la implantación de los estudios oficiales de Grado en Música, Arte Dramático y Diseño en el ámbito de la Comunidad Autónoma de Canarias, al no insertarse los anexos I, II y III (BOC no 91, de 9.5.11). Boletín Oficial de Canarias del 19 de mayo de 2011, no 99, referencia 2678, pp. 12053-12118.

Resolución de 25 de julio de 2013, de la Dirección General de Formación Profesional y Educación de Personas Adultas, por la que se establece para la Comunidad Autónoma de la Región de Murcia el plan de estudios y la ordenación de los estudios superiores de Música, se completan los planes de estudios iniciados en los años académicos 2010-2011 y 2011-2012 y se regula la prueba específica de acceso. Boletín Oficial de la Región de Murcia del 16 de agosto de 2013, no 189, referencia 12504, pp. 33079-33249.

\section{Recursos de Internet}

Álvarez González, C. Las salidas profesionales de un/una violinista. Resonancias, 4, pp. 62-68. [En línea]. Disponible en http://ria.asturias.es/RIA/ bitstream/123456789/228/1/Covadonga_Alvarez.pdf

Pliego de Andrés, V. De músicas, normas y conservatorios. [En línea]. Disponible en http://www.sonograma.org/webdemusica/wp-content/uploads/normativa-loe/1_8.pdf

Pliego de Andrés, V. Las enseñanzas superiores de música ante la nueva reforma: análisis y propuestas. Trabajadores de la Enseñanza, 283. [En línea]. Disponible en http://www.sonograma.org/ webdemusica/wp-content/uploads/ normativa-loe/2_17.pdf 
Pliego de Andrés, V. Los conservatorios de música en el proyecto de Ley Orgánica de Educación. [En línea]. Disponible en http://www.sonograma.org/webdemusica/wp-content/uploads/normativaloe/1_2.pdf
Pliego de Andrés, V. Los conservatorios superiores y la universidad. [En línea]. Disponible en http://www.sonograma.org/ webdemusica/wp-content/uploads/ normativa-loe/2_7.pdf 